\title{
On the Analysis of LF Ionospheric Radio Propagation Phenomena*
}

\author{
J. Ralph Johler \\ Contribution From Central Radio Propagation Laboratory, National Bureau of Standards, Boulder, Colo.
}

(Received April 27, 1961)

\begin{abstract}
Recent theoretical work which employs the classical magneto-ionic theory for a special model of the ionosphere applicable to transmission via the ionosphere at or close to grazing incidence is employed to analyze LF propagation data. The results of the analysis illustrate a practical model of the ionosphere by a detailed study of transmission via the first timemode in particular.
\end{abstract}

\section{Introduction}

Recent contributions and extensions to the classical geometric-optical theory of propagation [Wait and Conda, 1958; Wait, 1960a; Johler and Walters, 1960, 1961] of LF waves about the earth provide a valuable analysis tool for the interpretation of various experimental data. This paper summarizes the mathematical formulas required to predict the field with particular emphasis on a type analysis most suitable for large scale electronic computers. Attention is focused on certain available experimental data and the results of the analysis are detailed with emphasis on technique. However, the physical phenomena which can be deduced as a result of the analysis of these data are given considerable attention to emphasize the value of the technique.

\section{Mathematical Theory}

A geometric-optical theory [Bremmer, 1949] can be employed with the aid of a sharply bounded model ionosphere [Johler and Walters, 1960, 1961] emplaced at various altitudes $h$ above a spherical earth to describe the $c w$ field, $E(\omega, d)$, radiated from a dipole source current moment, $I_{0} l$. It is common engineering practice at LF to relate the amplitude of the field, $|E(\omega, d)|$ to the well known concept of radiated power [Ballentine, 1924], neglecting earth losses,

$$
P_{r}=1.6\left(10^{-13}\right) \omega^{2}\left(I_{0} l\right)^{2} / Z_{0},
$$

where $Z_{0} \sim 120 \pi$, a constant. Such a field, $E(\omega, d)$, implies a similar Hertzian dipole receiver (vertical polarization). The total field, $E(\omega, d)$, is the sum of $j+1$ reflected ionospheric waves, $j=0,1,2,3 \ldots$,

$$
E(\omega, d)=\sum_{j=0}^{p} E_{j}(\omega, d)
$$

in which the zero order $(j=0)$ reflection, $E_{0}(\omega, d)$ is the groundwave. Each skywave reflection, $j=1,2,3 \ldots$, using the positive time function, $\exp (i \omega t)$, can be written,

$$
E_{j}(\omega, d)=i \omega d D_{j}^{-1} C \exp \left(i \omega t_{j}^{\prime}\right) G_{j}^{t} G_{j}^{r} \alpha_{j} F_{j} C_{j},
$$

where [Johler, Kellar, and Walters, 1956],

and where,

$$
E_{0}(\omega, d)=\left[E_{0}(\omega, d)\right] \exp \left[-i\left(\omega b+\phi_{c}\right)\right],
$$

$$
C=I_{0} l b^{2} / 4 \pi \kappa d^{3}=\left(10^{-7}\right) / d,\left(I_{0} l=1\right) .
$$

The local time ${ }^{1}$ for the groundwave, $t_{0}^{\prime}$ is,

$$
\begin{aligned}
t_{0}^{\prime} & =t-b, \\
b & =\eta_{1} d / c,
\end{aligned}
$$

*This is a revised version of a paper presented at the A vionics Panel Meeting of the Advisory Goup for Aeronautical Research and Development (AGARD) NATO, Istanbul, Turkey, October 1960.

1 The notion of local time was apparently introduced by Lorentz [1906, p. 57]. 


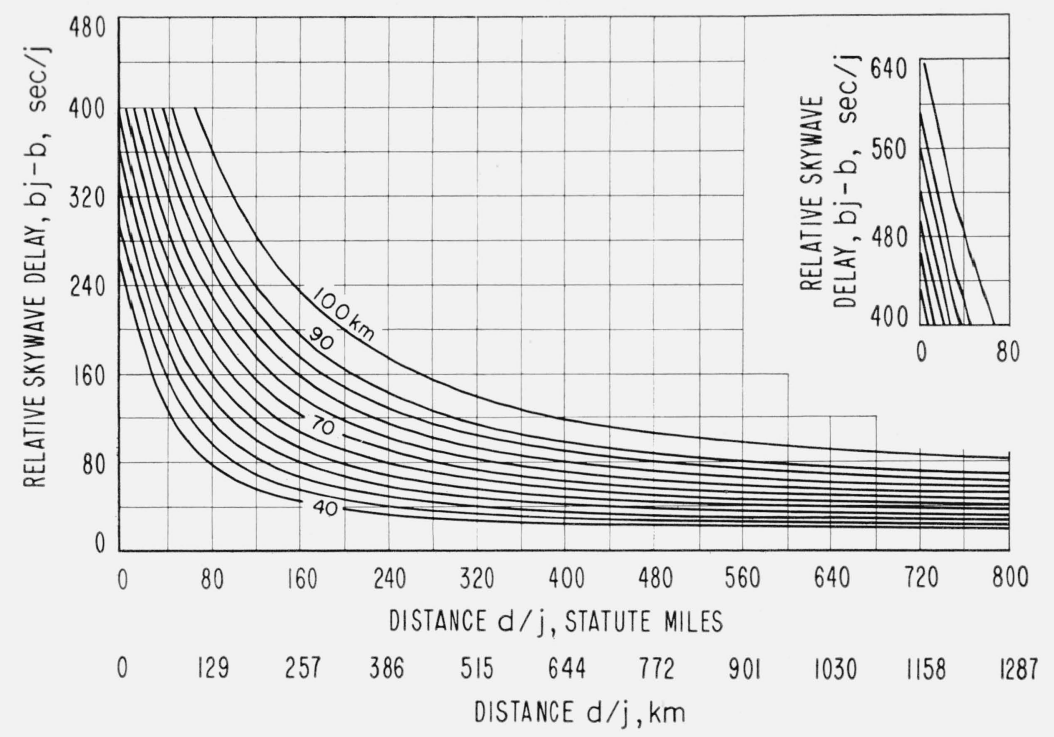

Figure 1. Relative sky wave delay for various altitude, $\mathrm{h}$, of the lower boundary of the model ionosphere.

where $c$ is the speed of light, $c \sim 3\left(10^{8}\right) \mathrm{m} / \mathrm{sec}$, and $\eta_{1}$ is the index of refraction of air, $\eta_{1} \sim 1$. Similarly, the local skywave time, or skywave delay, $t_{j}^{\prime}(j=1,2,3 \ldots$. .) is,

$$
\begin{gathered}
t_{j}^{\prime}=t-b_{j}, \\
b_{j}=\eta_{1} D_{j} / c,(j=1,2,3 \ldots .) .
\end{gathered}
$$

The quantity, $b_{j}-b$, is frequently called the relative skywave delay, figure 1 (relative to the groundwave). The physical length of the ray, $D_{j}$, can be evaluated geometrically for a reflection at an altitude, $h$, above the surface of the earth of radius, $a$,

$$
D_{j}=2 j\left[(a+h) \cos \phi_{i, j}-a \cos \tau_{j}\right],
$$

where, figures $2,3, \phi_{i}$ is the angle of incidence of the "ray" on the ionosphere and $\tau_{j}$ is the

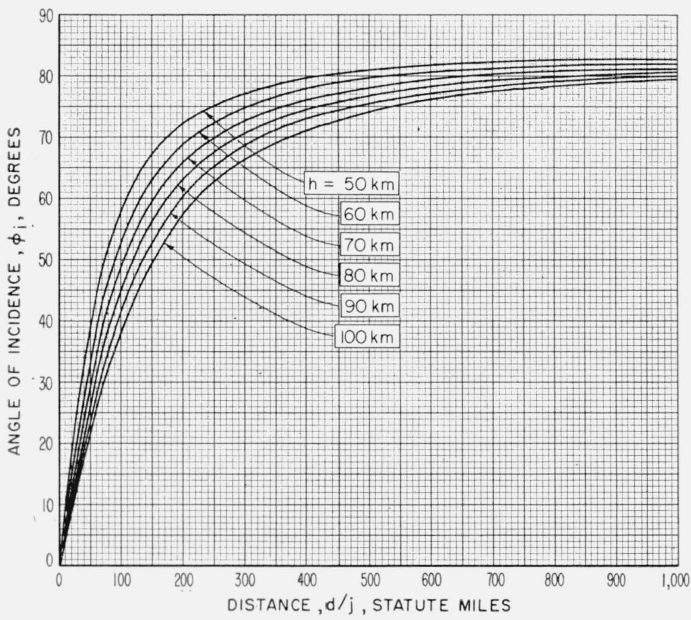

Figure 2. Geometric-optical relation between the angle of incidence, $\phi_{\mathrm{i}}$, distance from the source, $\mathrm{d} / \mathrm{j}$ ( $\mathrm{j}=$ order of sky wave hop or time-mode, $\mathrm{j}=1,2$, $3 . .$.$) and altitude of the boundary of the model$ ionosphere, $\mathrm{h}$.

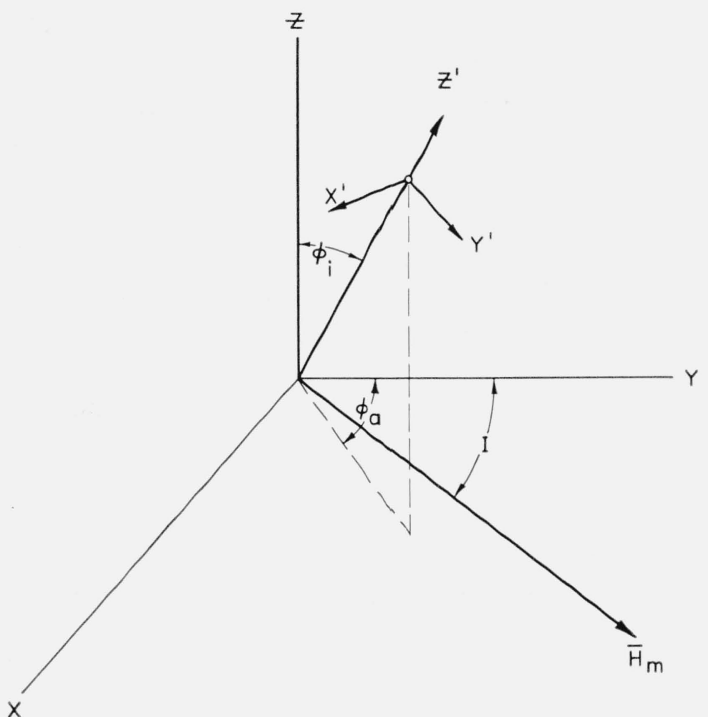

Figure 3. Coordinate systems at the ionosphere boundary. 
corresponding angle of incidence on the earth and the subscript " $j$ " reminds the reader that the equation refers to the particular ionospheric reflection under consideration. The angles $\phi_{i}$ and $\tau_{j}$ are evaluated quite simply from the geometry,

$$
\begin{gathered}
\sin \phi_{i, j}=\Delta_{j}^{-1} a \sin \frac{\theta}{2 j}, \\
\cos \phi_{i, j}=\Delta_{j}^{-1}[a(1-\cos \theta / 2 j)+h], \\
\sin \tau_{j}=\Delta_{j}^{-1}(a+h) \sin \theta / 2 j, \\
\cos \tau_{j}=\Delta_{j}^{-1}[a(\cos \theta / 2 j-1)+h \cos \theta / 2 j), \\
\Delta_{j}=\left[2 a(a+h)(1-\cos \theta / 2 j)+h^{2}\right]^{\frac{1}{2}},
\end{gathered}
$$

where $\theta$ is the angle at the center of the earth subtended by the distance, $d$, along the surface of a spherical earth, or, simply,

$$
d=a \theta .
$$

The factors, $G_{j}^{t}$ and $G_{j}^{r}$ refer to the transmitter and receiver complex antenna patterns respectively, and again the subscript, " $j$ ", is employed to designate the particular time-mode under consideration. The vertically polarized Hertzian dipoles considered in this paper reduce to, $G_{j}^{t}=G_{j}^{r}=\sin \tau_{j}$. Of course, other antenna complex pattern factors can be introduced.

Since plane reflection coefficients are employed in this analysis, the convergence-divergence coefficient, $\alpha_{j}$, is necessary to convert the plane reflection coefficients to spherical reflection coefficients or from the viewpoint of "ray theory" it is necessary to take account of ray focusing by the ionosphere and a corresponding defocusing of rays by the earth. The "classical" convergence-divergence is modified by a "convergence correction" [Wait, 1959], $A_{j}$, in this paper, since the values of the first time-mode studied are at distances close to the "caustic" of rays or geometric-optical horizon, and hence the complete expression, $\alpha_{j}$,

$$
\alpha_{j}=(1+h / a)[(2 j \sin \theta / 2 j) / \sin \theta]^{\frac{1}{2}} \times\{[a(1-\cos \theta / 2 j)+h] /[(a+h) \cos \theta / 2 j-a]\}^{\frac{1}{2}} A_{j},
$$

in which $A_{j}$ can be evaluated from the cylindrical Hankel function of order, $n=\frac{1}{3}$, of the second kind,

$$
\begin{aligned}
& A_{j} \sim\left[\frac{\pi}{2} k_{1} a \cos ^{3} \tau_{j} / 3 \sin ^{2} \tau_{j}\right]^{\frac{1}{2}} H_{\frac{1}{3}}^{(2)}\left[k_{1} a \cos ^{3} \tau_{j} / 3 \sin ^{2} \tau_{j}\right] \\
& \times \exp \left\{-i\left[5 \pi / 12-k_{1} a \cos ^{3} \tau_{j} / 3 \sin ^{2} \tau_{j}\right]\right\} .
\end{aligned}
$$

The factor, $\mid A_{j}$, approaches unity $\left(A_{j} \sim 1\right)$ at shorter distances, $\left(\tau_{j} \ll \pi / 2\right)$. Near the geometricoptical-horizon, $\tau_{j} \sim \pi / 2$, and beyond, the correction becomes quite appreciable. The Hankel functions, $H_{n}^{(2)}(z)$ can be readily evaluated on an electronic computer by a consideration of the integral form,

$$
H_{n}^{(2)}(z)=\frac{1}{\pi} \int_{0}^{\pi} \exp (-i z \sin \rho+i n \rho) d \rho-\frac{1}{\pi i} \int_{0}^{\infty} \exp (-z \sinh \rho)\{\exp n \rho+\exp (-n \rho+i n \pi)\} d \rho,
$$

where the order, $n=\frac{1}{3}$, and the argument, $z=k_{1} a \cos ^{3} \tau_{j} / 3 \sin ^{2} \tau_{j}$, in which the wave number, $k_{1}=\omega \eta_{1} / c \sim \omega / c$, for the case under consideration are real numbers. Nevertheless, it is interesting to note that the method is also applicable to complex argument, $z$, and complex order, $n$, provided the multiple branches of the Hankel function are carefully considered. The following substitution is made,

$$
\beta=\exp (-\rho)
$$

and a resultant expression for the Hankel function. 


$$
H_{n}^{(2)}(z)=\frac{1}{\pi} \int_{0}^{\pi} \exp (-i z \sin \rho+i n \rho) d \rho-\frac{1}{\pi i} \int_{0}^{1}\left[\beta^{-n-1}+\beta^{n-1} \exp (i n \pi)\right] \exp \left[-\frac{z}{2}\left(\frac{1}{\beta}-\beta\right)\right] d \beta
$$

or,

$$
H_{n}^{(2)}(z)=\int_{0}^{\pi} f(z, \rho, n) d \rho-\int_{0}^{1} f(z, \beta, n) d \beta,
$$

is found to comprise integrals with finite limits. These integrals can then be evaluated in terms of Gaussian quadrature, ${ }^{2}$

$H_{n}^{(2)}(z)=\sum_{m=1}^{M} W_{m}^{\rho}\left[\operatorname{Re} f\left(z, \rho_{m}, n\right)+i \operatorname{Im} f\left(z, \rho_{m}, n\right)\right]-\sum_{m=1}^{M} W_{m}^{\beta}\left[\operatorname{Re} f\left(z, \beta_{m}, n\right)+i \operatorname{Im} f\left(z, \beta_{m}, n\right)\right]+\epsilon(M)$

$m=1,2,3 \ldots M$, where, $\epsilon(M)$ can be made arbitrarily small by increasing $M$,

where,

$$
\begin{aligned}
W_{m}^{\rho} & =\pi H_{m} / 2, \\
W_{m}^{\beta} & =H_{m} / 2, \\
\rho_{m} & =\pi x_{m} / 2+\pi / 2, \\
\beta_{m} & =x_{m} / 2+1 / 2,
\end{aligned}
$$

and the constants, $x_{m}$, of the theory of Gaussian quadrature can be evaluated as the roots of the Legendre polynomials defined by,

$$
\frac{d^{M}}{d x}\left(x^{2}-1\right)^{M}-2^{M} M ! P_{M}(x)=0,
$$

or,

$$
\begin{aligned}
& P_{0}(x)=1, \\
& P_{1}(x)=x, \\
& P_{2}(x)=\frac{3}{2} x^{2}-\frac{1}{2}, \\
& P_{3}(x)=\frac{5}{2} x^{3}-\frac{3}{2} x, \\
& P_{4}(x)=\frac{35}{8} x^{4}-\frac{15}{4} x^{2}+\frac{3}{8}, \\
& \ldots .
\end{aligned}
$$

where polynomials of higher degree are determined by the use of the recursion formula,

$$
(M+1) P_{M+1}(x)+M P_{M-1}(x)-(2 M+1) x P_{M}(x)=0 .
$$

The weight coefficients, $H_{m}$, are evaluated from the roots, $x_{m}$,

$$
H_{m}=2 /\left(1-x_{m}^{2}\right)\left[P_{M}^{\prime}\left(x_{m}\right)\right]^{2} .
$$

The factor, $F_{j}$, accounts for the presence of the earth at the transmitter (source) and receiver. If it can be assumed that the "ray" reflected by the earth is not too close or beyond" the geometric-optical horizon, the Fresnel approximation of the ground reflection coefficient suffices to determine $F_{j}$, or,

$$
F_{j} \sim\left[1+R_{e}^{t}\left(\tau_{j}\right)\right]\left[1+R_{e}^{r}\left(\tau_{j}\right)\right],
$$

:This type analysis has been used extensively by the author in previous papers to evaluate Fourier integrals [Johler and Walters, 1959]. 
where the superscripts, $t$ and $r$, refer to the transmitter and receiver respectively and the subscript, $e$, refers to vertical polarization, and,

$$
R_{e}\left(\tau_{j}\right)=\left\{k_{2}^{2} \cos \tau_{j} / k_{1}^{2}-\left[k_{2}^{2} / k_{1}^{2}-\sin ^{2} \tau_{j}\right]^{\frac{1}{2}}\right\} /\left\{k_{2}^{2} \cos \tau_{j} / k_{1}^{2}+\left[k_{2}^{2} / k_{1}^{2}-\sin ^{2} \tau_{j}\right]^{\frac{1}{2}}\right\},
$$

or for horizontal polarization,

where,

$$
R_{m}\left(\tau_{j}\right)=\left\{\cos \tau_{j}-\left[k_{2}^{2} / k_{1}^{2}-\sin ^{2} \tau_{j}\right]^{\frac{1}{2}}\right\} /\left\{\cos \tau_{j}+\left[k_{2}^{2} / k_{1}^{2}-\sin ^{2} \tau_{j}\right]^{\frac{1}{2}}\right\},
$$

$$
k_{2}=\frac{\omega}{c}\left[\epsilon_{2}-i \frac{\sigma \mu_{0} c^{2}}{\omega}\right]^{\frac{1}{2}}
$$

and $\epsilon_{2}$ is the dielectric constant of the earth $\left(\epsilon_{2} \sim 15\right)$ and $\sigma$ is the conductivity of the earth $(\sigma \sim 0.005$ for land). Since the examples considered in this paper involve distances which, for the first time-mode, were close to the geometric-optical horizon, it was found necessary to replace the Fresnel reflection coefficients with a more rigorous treatment.

Close to the geometric-optical horizon a calculation of $F_{j}=F_{j}^{t} F_{j}^{r}$ can be accomplished by a numerical evaluation of the contour integral, [Wait and Conda, 1958],

$$
F_{j}^{t, r} \sim(\pi)^{-\frac{1}{2}} \exp \left[-i k_{1} a \theta^{\prime}\right] \int_{\infty \exp [-i 2 \pi / 3]}^{\infty} \exp \left[-i\left(k_{1} a / 2\right)^{\frac{1}{3}} \theta^{\prime} \rho\right] / W_{1}^{\prime}(\rho)-q W_{1}(\rho) d \rho,
$$

$\theta^{\prime}=\left(d-d_{H}\right) / a$, where $d_{H}$ is the distance ${ }^{3}$ from transmitter to the geometric-optical horizon $\left(\tau_{j} \sim \pi / 2\right)$ and,

$$
q=-i\left(\frac{k_{1} a}{2}\right)^{\frac{1}{3}} \frac{k_{1}}{k_{2}} \sqrt{1-\frac{k_{1}^{2}}{k_{2}^{2}}}
$$

in which $\sigma=\sigma_{2}$ is the ground conductivity at either transmitter $F_{j}^{t}$ or receiver $F_{j}^{r}$ and $\epsilon_{2}$ is the corresponding dielectric constants (relative to a vacuum), and,

$$
\begin{gathered}
W_{1}(\rho)=\exp [-2 \pi i / 3] \sqrt{\pi / 3}(-\rho)^{\frac{1}{2}} H_{\frac{1}{3}}^{(2)}\left[2 / 3(-\rho)^{\frac{3}{2}}\right], \\
W_{1}^{\prime}(\rho)=\exp [-2 \pi i / 3] \sqrt{\pi / 3}\left\{-\frac{1}{2}(-\rho)^{-\frac{1}{2}} H_{\frac{1}{3}}^{(2)}\left[\frac{2}{3}(-\rho)^{\frac{3}{2}}\right]+\rho H_{\frac{1}{3}}^{\prime(2)}\left[\frac{2}{3}(-\rho)^{\frac{3}{2}}\right]\right\}, \\
W_{1}^{\prime}(\rho)=\exp [-i 4 \pi / 3] \sqrt{\pi / 3} \rho H_{\frac{3}{3}}^{(2)}\left[\frac{2}{3}(-\rho)^{\frac{3}{2}}\right] \\
H_{\frac{1}{3}}^{\prime(2)}(Z)=\frac{d}{d Z} H_{\frac{1}{3}}^{(2)}(Z)=\exp [-i 2 \pi / 3] H_{\frac{2}{3}}^{(2)}(Z)-\frac{1}{3 Z} H_{\frac{1}{3}}^{(2)}(Z) .
\end{gathered}
$$

The Hankel functions $H_{\frac{1}{3}}^{(1,2)}(Z)$ can be calculated by previously described quadrature methods (20-27). The contour integral can be written [Wait, 1960b],

$$
F_{j}^{t, r}=(\pi)^{-\frac{1}{2}} \exp \left[-i k_{1} a \theta^{\prime}\right]\left\{\int_{0}^{\infty} \frac{\exp \left[-i\left(k_{1} a / 2\right)^{\frac{1}{3}} \theta^{\prime} \alpha\right]}{W_{1}^{\prime}(\alpha)-q W_{1}(\alpha)} d \alpha-\int_{0}^{\infty} \frac{\exp \left[-i\left(k_{1} a / 2\right)^{\frac{1}{3}} \theta^{\prime} \alpha^{\prime}\right]}{W_{1}^{\prime}\left(\alpha^{\prime}\right)-q W_{1}\left(\alpha^{\prime}\right)} d \alpha^{\prime}\right\},
$$

$\alpha^{\prime}=\alpha \exp (-i 2 \pi / 3)$. These integrals can then be evaluated with a Gaussian quadrature.

Close to but beyond the geometric-optical horizon $\left(\tau_{j} \sim \pi / 2\right)$ [Wait and Conda, 1958], a calculation can be performed as a residue series summation,

$$
F_{j}^{r, t} \sim-2 i \sqrt{\pi} \exp \left[-i k_{1}\left(d-d_{H}\right)\right] \sum_{s=0}^{\infty} \frac{\exp \left[-i\left(k_{1} a\right)^{\frac{1}{2}} \theta^{\prime} \tau_{s}^{*}\right]}{\left(2^{\frac{1}{3}} \tau_{s}^{*}-q^{2}\right) W_{1}\left(2^{\frac{1}{3}} \tau_{s}^{*}\right)}
$$

\footnotetext{
${ }^{3} a \sim 6.367\left(10^{6}\right) \mathrm{m}$. In diffraction problems it is common practice to account for the vertical lapse of the permittivity of air at the earth's surface by use of an "effective earth radius", $a_{e}$ in place of $a$ such that $\frac{a}{a_{e}} \sim 0.75-0.85$, [Bremmer, 1949, p. 145].
} 
where the complex conjugate $\tau_{s}$ of $\tau_{s}^{*}$ comprises the special roots of the differential equation of Riccati tabulated by Johler, Walters, and Lilley [1959], employing the time function, $\exp (-i \omega t)$,

where

$$
\frac{d \delta_{e}}{d \tau_{s}}-2 \tau_{s} \delta_{e}^{2}+1=0
$$

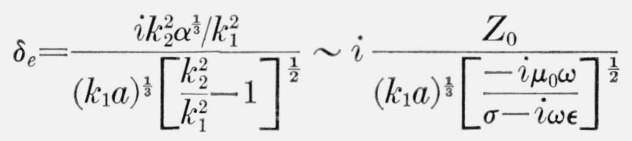

and, $k_{1}=\frac{\omega}{c} \eta_{1} \sim \frac{\omega}{c}, k_{2}^{*}$, implies the complex conjugate of $k_{2}$, (3), and the limiting roots are found from the equations,

$$
\begin{aligned}
H_{\frac{2}{3}}^{(1)}\left[\frac{1}{3}\left(-2 \tau_{s}\right)^{\frac{3}{2}}\right] & =0, \delta_{e}=\infty, \\
H_{\frac{1}{3}}^{(1)}\left[\frac{1}{3}\left(-2 \tau_{s}\right)^{\frac{3}{2}}\right] & =0, \delta_{e}=0, \\
s & =0,1,2,3 \ldots .
\end{aligned}
$$

Finally, the effective reflection coefficient of geometric-optics, $C_{j}$, can be evaluated for vertical polarization,

where,

$$
C_{j}=\frac{1}{j ! R_{e}} \frac{d^{j}}{d x^{j}}\left[\frac{1+A_{1} x}{1-A_{2} x-A_{3} x^{2}}\right]_{x=0},
$$

$$
\begin{aligned}
& A_{1}=-R_{m} T_{m m} \\
& A_{2}=R_{e} T_{e e}+R_{m} T_{m m} \\
& A_{3}=R_{e} R_{m}\left[-T_{e e} T_{m m}+T_{e m} T_{m e}\right] .
\end{aligned}
$$

Thus, the essential nature of the propagation about the earth via the ionosphere can be described in terms of four reflection coefficients, $T_{e e}, T_{e m}, T_{m e}$, and $T_{m m}$. The reflection coefficient, $T_{c e}$, refers to the vertical electric polarization of the incident plane wave and a similar vertical electric polarization of the reflected wave. The coefficient, $T_{e m}$, describes the generation of the abnormal component by the incident vertical polarization (reflected horizontal polarization for vertical excitation). Similarly, $T_{m m}$ refers to the incident horizontal electric polarization and the corresponding reflected horizontal electric polarization. Also, the abnormal componeut generated by the horizontal electric polarization (reflected vertical polarization for horizontal excitation) is described by the coefficient, $T_{m e}$. Thus, figure 3 ,

$$
T_{e e}=E_{y^{\prime} r}^{\prime} / E_{y^{\prime} i}, T_{m m}=E_{x^{\prime} r} / E_{x^{\prime} i}, T_{e m}=E_{x^{\prime} r} / E_{y^{\prime} i}, T_{m e}=E_{y^{\prime} r} / E_{x^{\prime} i}
$$

where the subscripts $i$ and $r$ refer to incident and reflected wave respectively at the ionosphere boundary. The calculation of these reflection coefficients has been previously described in detail and the results of various computations have been tabulated [Johler and Walters, 1960].

The reflection coefficients are completely specified by the angle of incidenc,$\phi_{i}$, figures 2,3 , electron density $N\left(\mathrm{El} / \mathrm{cm}^{3}\right)$, figure 4, collision frequency $\nu(\mathrm{c} / \mathrm{s})$, figure 5, magnetı field intensity $H_{m}$ (gauss), magnetic dip $I$ and magnetic azimuth $\phi_{a}$. The effective reflection coefficients, $C_{j}$, can then be written in terms of the ionosphere reflection coefficients, $T$, and the ground reflection coefficients, $R$, for each local ionosphere or ground reflection,

$C_{1}=C_{1}\left(\tau_{1}\right)=T_{e e}$,

$C_{2}=C_{2}\left(\tau_{2}\right)=T_{e e_{1}} T_{e e_{2}} R_{e_{1}}+R_{m_{1}} T_{e m_{1}} T_{m e_{2}}$,

$C_{3}=C_{3}\left(\tau_{3}\right)=R_{e_{2}} R_{m_{1}} T_{e e_{3}} T_{e m_{1}} T_{m e_{2}}+R_{e_{1}} R_{m_{2}} T_{e e_{1}} T_{e m_{1}} T_{m e_{3}}+R_{e_{1}} R_{e_{2}} T_{e e_{1}} T_{e e_{2}} T_{e e_{3}}+R_{m_{1}} R_{m_{2}} T_{m m_{2}} T_{e m_{1}} T_{m e_{3}}$, 


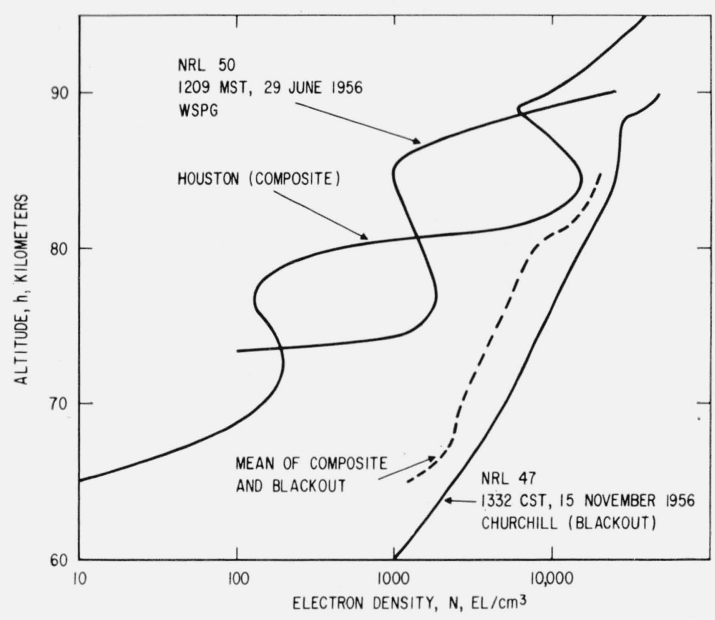

Figure 4. Electron density-altitude, N(h), profiles of the lower ionosphere deduced from various radio and rocket measurements.

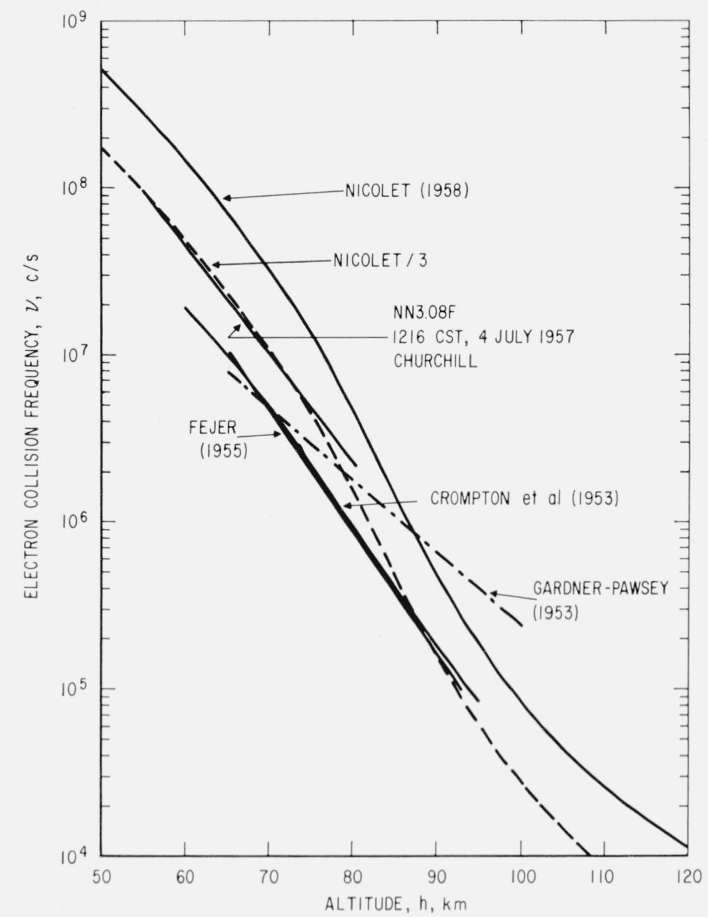

Figure 5. Collision frequency-altitude, $\nu(\mathrm{h})$, profiles of the lower ionosphere deduced from theory and various rocket measurements.

$$
\begin{aligned}
C_{4}= & C_{4}\left(\tau_{4}\right)=R_{e_{1}} R_{e_{2}} R_{e_{3}} T_{e e_{4}} T_{e e_{3}} T_{e e_{2}} T_{e e_{1}}+R_{e_{1}} R_{e_{2}} R_{m_{3}} T_{m e_{4}} T_{e m_{3}} T_{e e_{2}} T_{e e_{1}}+R_{e_{1}} R_{m_{2}} R_{e_{3}} T_{e e_{4}} T_{m e_{3}} T_{e m_{2}} T_{e e_{1}} \\
& +R_{e_{1}} R_{m_{2}} R_{m_{3}} T_{m e_{4}} T_{m m_{3}} T_{e m_{2}} T_{e e_{1}}+R_{m_{1}} R_{e_{2}} R_{e_{3}} T_{e e_{4}} T_{e e_{3}} T_{m e_{2}} T_{e m_{1}}+R_{m_{1}} R_{e_{2}} R_{m_{3}} T_{m e_{4}} T_{e m_{3}} T_{m e_{2}} T_{e m_{1}} \\
& +R_{m_{1}} R_{m_{2}} R_{e_{3}} T_{e e_{4}} T_{m e_{3}} T_{m m_{2}} T_{e m_{1}}+R_{m_{1}} R_{m_{2}} R_{m_{3}} T_{m e_{4}} T_{m m_{3}} T_{m m_{2}} T_{e m_{1}},
\end{aligned}
$$

where the subscripts $1,2,3,4 \ldots$ refer to the first, second, third, fourth, etc., reflection regions of the ionosphere with corresponding separate values for electron density, $N$, collision frequency, $\nu$, and the intensity and direction of the earth's magnetic field vector, $\bar{H}_{m}$, or, for the ground, refer to the separate values of conductivity, $\sigma$, and dielectric constant, $\epsilon_{2}$.

For a homogeneous ionosphere and ground with a single set of values, $N, v, \bar{H}_{m}$, $\sigma$, and $\epsilon_{2}$, the effective reflection coefficients, $C_{j}$, reduce as follows:

$$
\begin{aligned}
& C_{1}=T_{e e} \\
& C_{2}=T_{e e}^{2} R_{e}+R_{m} T_{e m} T_{m e} \\
& C_{3}=2 R_{e} R_{m} T_{e e} T_{e m} T_{m e}+R_{e}^{2} T_{e e}^{3}+R_{m}^{2} T_{m m} T_{e m} T_{m e} \\
& C_{4}=R_{e} R_{m}^{2} T_{e m}^{2} T_{m e}^{2}+3 R_{e}^{2} R_{m} T_{e e}^{2} T_{e m} T_{m e}+2 R_{e} R_{m}^{2} T_{e e} T_{m m} T_{e m} T_{m e}+R_{m}^{3} T_{m m}^{2} T_{e m} T_{m e}+R_{e}^{3} T_{e e}^{4}, \\
& \ldots
\end{aligned}
$$

The wave number of the ionosphere propagation medium,

$$
\begin{aligned}
k_{3} & =\frac{\omega}{c} \eta_{0}, \\
& =\frac{\omega}{c} \eta_{e},
\end{aligned}
$$

implies two upgoing waves excited in the model ionosphere with index of refraction, $\eta_{0}$, for 
the "ordinary" wave and index of refraction, $\eta_{e}$, for the "extraordinary" wave. The value of the reflection coefficients, $T$, are related to the $\eta_{0}$ and $\eta_{e}$.

The rate of attenuation and phase lag of the wave, $\bar{E}_{t}$, transmitted into the ionosphere can be deduced by an interpretation of the transmitted wave in terms of the complex index of refraction, $\eta=\eta_{0, e^{\prime}}$

$$
E_{t}=\left|\bar{E}_{t}\right| \exp \left\{i\left[\omega t-\frac{\omega}{c} \eta D\right]\right\}
$$

The amplitude is as follows:

$$
\exp \left\{\frac{\omega}{c} \operatorname{Im} \eta D\right\}, \exp \{\text { nepers }\}
$$

or the amplitude change is,

$$
\begin{gathered}
\exp \left\{\frac{\omega}{c} \operatorname{Im} \eta 10^{3}\right\}, \exp \{\text { nepers } / \mathrm{km}\}, \\
\text { or, } 8.686 \frac{\omega}{c} \operatorname{Im} \eta D, \text { decibels, } \\
\text { or, } 8.686 \frac{\omega}{c} \operatorname{Im} \eta 10^{3}, \mathrm{db} / \mathrm{km},
\end{gathered}
$$

where $D$ (meters) is the penetration distance into the ionosphere. The corresponding phase $\operatorname{lag}$ is,

$$
\frac{\omega}{c} \operatorname{Re} \eta D \text { radians, }
$$

or,

$$
\frac{\omega}{c} \operatorname{Re} \eta\left(10^{3}\right) \text { radians } / \mathrm{km} \text {. }
$$

\section{Analysis of Experimental Data}

Although there is a tendency in LF propagation studies to separate arctic-auroral phenomena from those phenomena observed at LF in temperate latitudes, the mechanism of propagation seems to differ only in the degree and frequency of the so-called disturbed and blackout conditions which characterize the arctic regions. Certain data on propagation at LF in both the arctic-auroral regions and the temperate regions are analyzed in this paper to demonstrate principle rather than deduce comprehensive engineering conclusions. A theoretical investigation and analysis is therefore attempted to gain some insight into LF propagation phenomena for Loran-C system evaluation.

Ionosphere electron density-altitude profiles $N(h)$, figure 4, and collision frequency-altitude profiles $\nu(h)$, figure 5, have recently been deduced with the aid of a theoretical method and an experimental HF signal transmitted through the ionosphere from rockets. Waynick [1957] reported the "Houston composite," figure $4 N(h)$ profile, and Seddon and Jackson [1958] have reported "NRL 50" and "NRL 47" profiles. Seddon and Jackson have also reported "NN3.08F" $\nu(h)$ profile, figure 5. Other $\nu(h)$ data are shown from Crompton et al. [1953], Gardner and Pawsey [1953], Fejer [1955], and Nicolet [1958].

The "Houston composite" $N(h)$ profile implies an interesting low electron density region at the 65 to $70 \mathrm{~km}$ altitudes of the lower ionosphere with values between $N=10$ and $N=100$ $\mathrm{El} / \mathrm{cm}^{3}$, figure 4 . Such a profile seemed to persist in the propagation data examined and profoundly influenced the daytime ionospheric propagation. However, it does not appear to exist in the "NRL 50" data which seems to give rise to great electron densities quite abruptly. Unfortunately, as a result of rocket drag considerations, the HF antennas were not extended until the rocket attained an altitude of about $55 \mathrm{~km}$, and measurements of electron densities in this region are not very detailed. This lack of data below $60 \mathrm{~km}$ is more apparent in the "NRL 47" data, observed in the auroral zone at Churchill, Canada, which illustrate a very large enhancement of the electron density during auroral "blackout" conditions. A "mean of the 
composite and blackout" profiles was employed as an intermediate "disturbed" model ionosphere.

Various collision frequency-altitude profiles, $\nu(h)$, are shown in figure 5. The "Nicolet/3" curve was used for all model ionospheres employed in this analysis. This is a theoretical curve substantiated with experimental rocket data. This theoretical curve is also consistent with other findings [Ratcliffe, 1959].

Theoretical field intensities, figures 6 to 9, were calculated for comparison with available data ${ }^{4}$ on LF transmission from Adak to Nome and Kodiak, Alaska. The independent variable
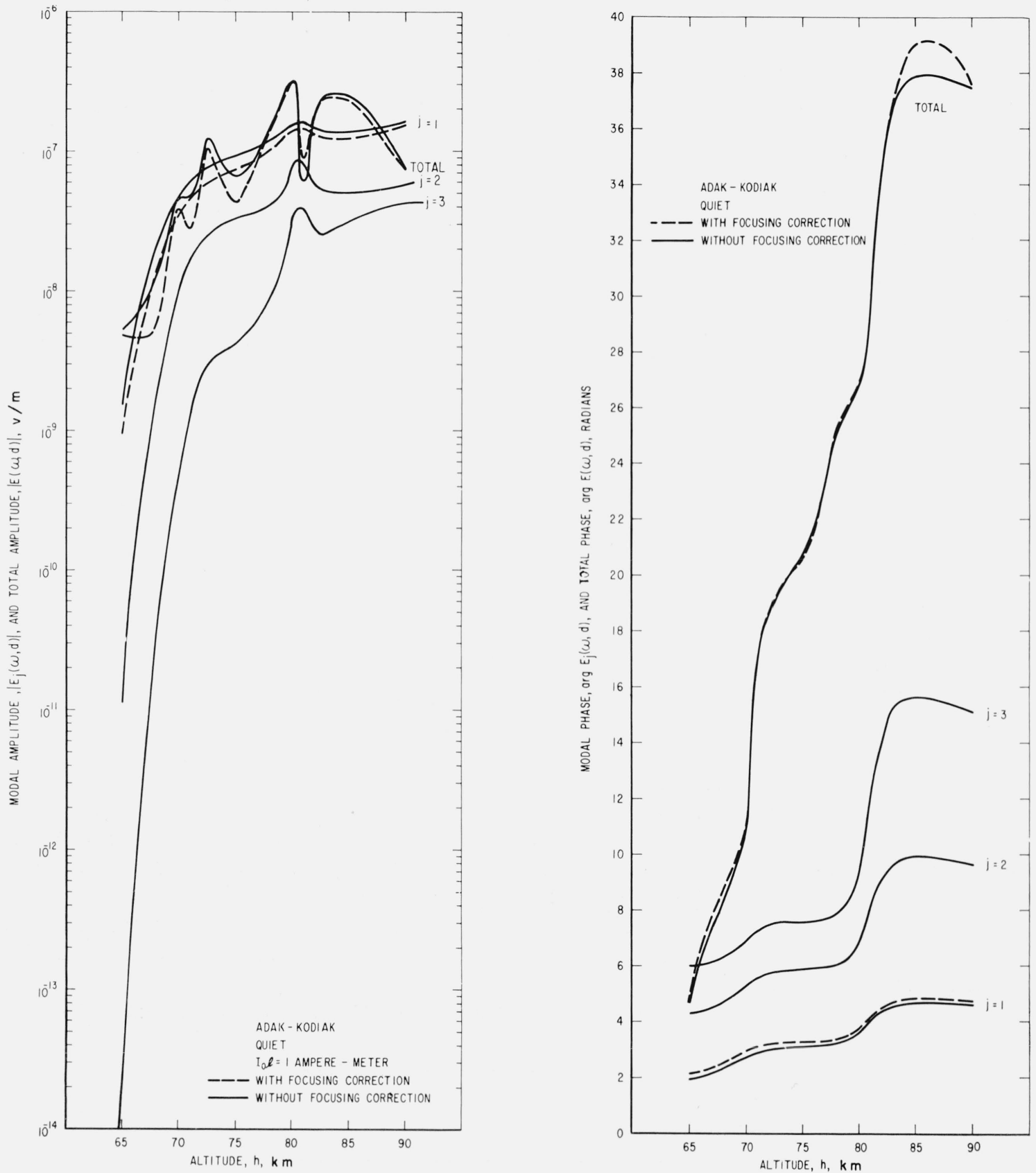

Figure 6. Total theoretical field $\mathrm{E}(\omega, \mathrm{d})$ for various fixed heights, $\mathrm{h}$, of sharply bounded model ionosphere for LF transmissions from Adak to Kodiak, Alaska.

(See figures 4 and 5 for electron density $\mathrm{N}$....)

4 The data employed in this analysis is treated somewhat differently from previous authors. The authors wish to thank A. D. Watt and J. E. Bickel for the use of their original data. See also Bickel [1959] and Watt et al. [1959]. 
of the calculations was the altitude, $h$, of the assumed sharply bounded model ionosphere. This implies a variation of the electron density according to the $N(h)$ profile as the variable $h$ is changed. Also, small adjustments in the angle of incidence, $\phi_{i}$, are implied.

Geophysical data on the ionosphere employed in the calculation are shown, tables 1, 2 . The magnetic data, shown in table 2, were scaled from Magnetic Charts [1954, 1957]. Apparently a nominal intensity value $H_{m}=0.5$ gauss (table 2) is an adequate assumption for many practical cases.

TABLE 1

\begin{tabular}{|c|c|c|c|c|}
\hline$h$ & $\nu$ & $N_{q}$ & $N_{d}$ & $N_{b}$ \\
\hline$k m$ & $\begin{array}{c}c / s, \times 10^{+6} \\
175\end{array}$ & $\mathrm{El} / \mathrm{cm}^{3}$ & $\mathrm{E} 1 / \mathrm{cm}^{3}$ & $\mathrm{El} / \mathrm{cm}^{3}$ \\
\hline $\begin{array}{l}60 \\
65\end{array}$ & $\begin{array}{l}50 \\
24\end{array}$ & 10 & 1205 & $\begin{array}{l}1000 \\
2400\end{array}$ \\
\hline 67.5 & 16 & 56 & & \\
\hline 70 & $\begin{array}{r}10.9 \\
9.2\end{array}$ & $\begin{array}{l}150 \\
180\end{array}$ & 2675 & 5200 \\
\hline 72.5 & $\begin{array}{l}9.2 \\
7\end{array}$ & 200 & & \\
\hline 75 & $\begin{array}{l}4.5 \\
2.6\end{array}$ & $\begin{array}{l}160 \\
140\end{array}$ & 4505 & 8850 \\
\hline $80^{\circ}$ & $\begin{array}{l}2.0 \\
1.6\end{array}$ & $\begin{array}{l}+0 \\
00\end{array}$ & 7950 & 15400 \\
\hline 81 & 1.2 & 3500 & 10550 & \\
\hline 82.5 & 0.88 & $\begin{array}{l}11000 \\
15000\end{array}$ & 16100 & 26000 \\
\hline $\begin{array}{l}85 \\
90\end{array}$ & $\begin{array}{l}.465 \\
.155\end{array}$ & $\begin{array}{l}15000 \\
10000\end{array}$ & 20500 & 26000 \\
\hline
\end{tabular}

TABLE 2.-Magnetic field, $\bar{H}_{\mathrm{m}}$, data

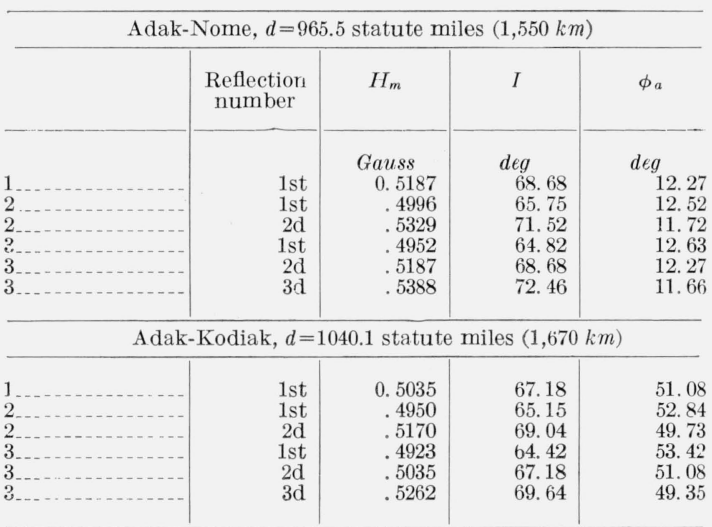

The modal (skywave time-mode) and the total (including the groundwave) calculated fields (amplitude and phase) for quiescent, disturbed, and blackout conditions of the ionosphere are presented, figures 6 to 9 . The effect of the ionosphere focusing corrections, $A_{j}$, is also illustrated, and, indeed, was found to be appreciable, both for the total field, $E(\omega, d)$, and the first modal field, $E_{j}(\omega, d), j=1$. The diffraction correction $F_{j}$ was also modified from the classical Fresnel reflection coefficient as discussed with the aid of calculated data of Wait and Conda [1958] which was installed in the electronic memory of a small computer. ${ }^{5}$

The ground wave, $E_{0}(\omega, d)$, which was calculated with the classical Bremmer-van der Pol theory [Johler, Kellar, and Walters, 1956] and corrected for land-sea boundaries with the aid of the Millington [1949] method is not shown alone graphically, since the groundwave is not a function of the emplacement altitude, $h$, but can be summarized as follows:

TABLE 3

\begin{tabular}{|c|c|c|c|}
\hline & \multicolumn{2}{|c|}{$E_{\mathrm{n}}(\omega, d)$} & \multirow{2}{*}{$\arg E_{0}(\omega, d)$} \\
\hline & $I_{\mathrm{o}} l=1$ & $I_{0} l=2050$ & \\
\hline $\begin{array}{l}\text { Nome } \\
\text { Kodiak }\end{array}$ & $\begin{array}{l}n / m \\
7.56\left(10^{-9}\right) \\
4.64\left(10^{-9}\right)\end{array}$ & $\begin{array}{c}v / m \\
1.55\left(10^{-5}\right) \\
9.51\left(10^{-6}\right)\end{array}$ & $\begin{array}{r}\text { Radians } \\
2.30 \\
2.43\end{array}$ \\
\hline
\end{tabular}

${ }^{5} \mathrm{IBM}-650$. 
All computations were made with the assumption of a dipole current moment, $I_{0} l=1$. The total radiated power, $P r=1.3 \mathrm{kw}$, for the arctic data considered was found to correspond to a dipole current moment, $I_{0} l=2050 \mathrm{amp}-\mathrm{m}$; therefore, the calculated field amplitude, $[E(\omega, d)]$, or $\left[E_{j}(\omega, d)\right]$, has been increased by this factor for comparison with the data.
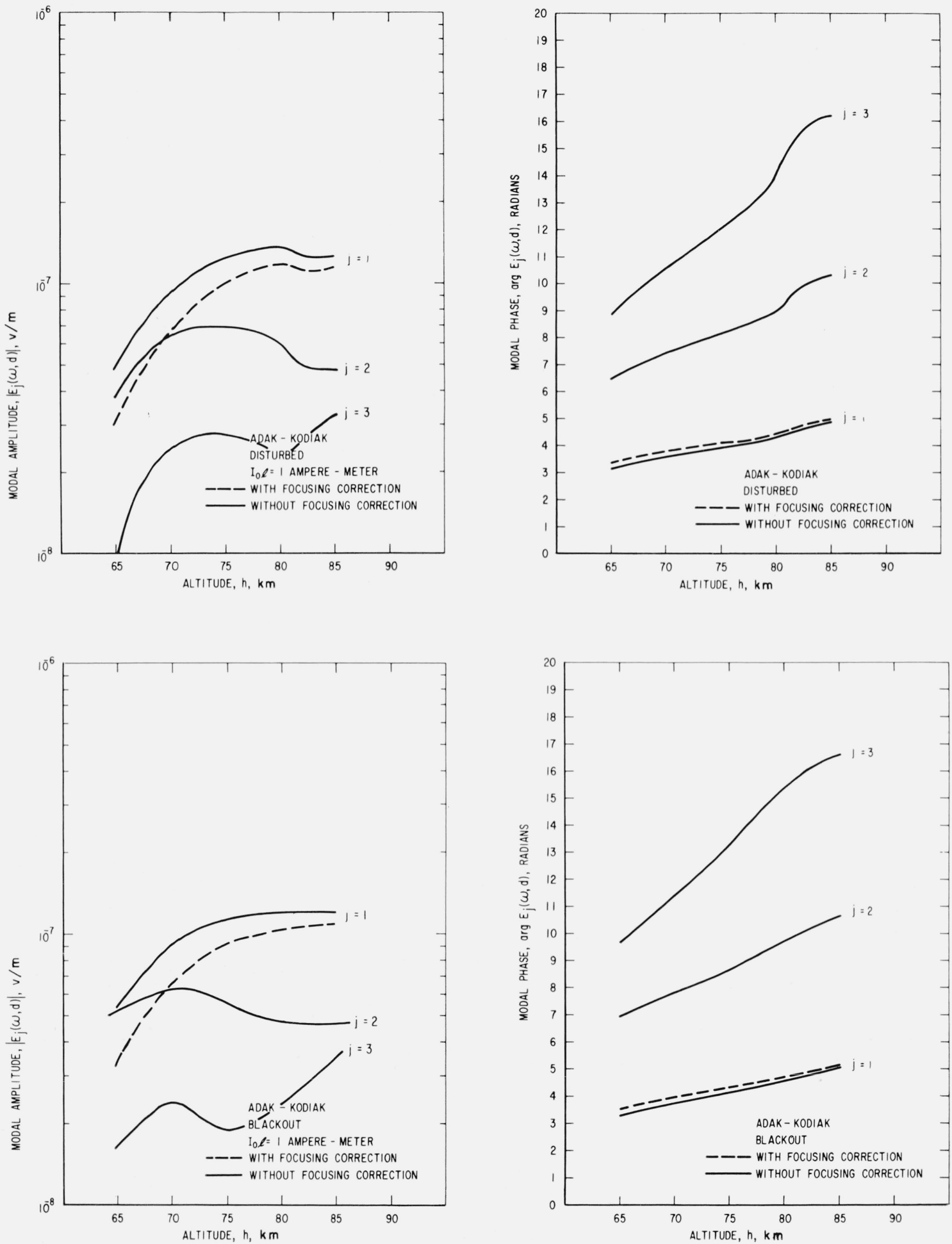

FIGURE 7. Disturbed-blackout theoretical field $\mathrm{E}(\omega, \mathrm{d})$ for various fixed heights, h, of sharply bounded model ionosphere for LF transmissions from Adak to Kodiak, Alaska. 

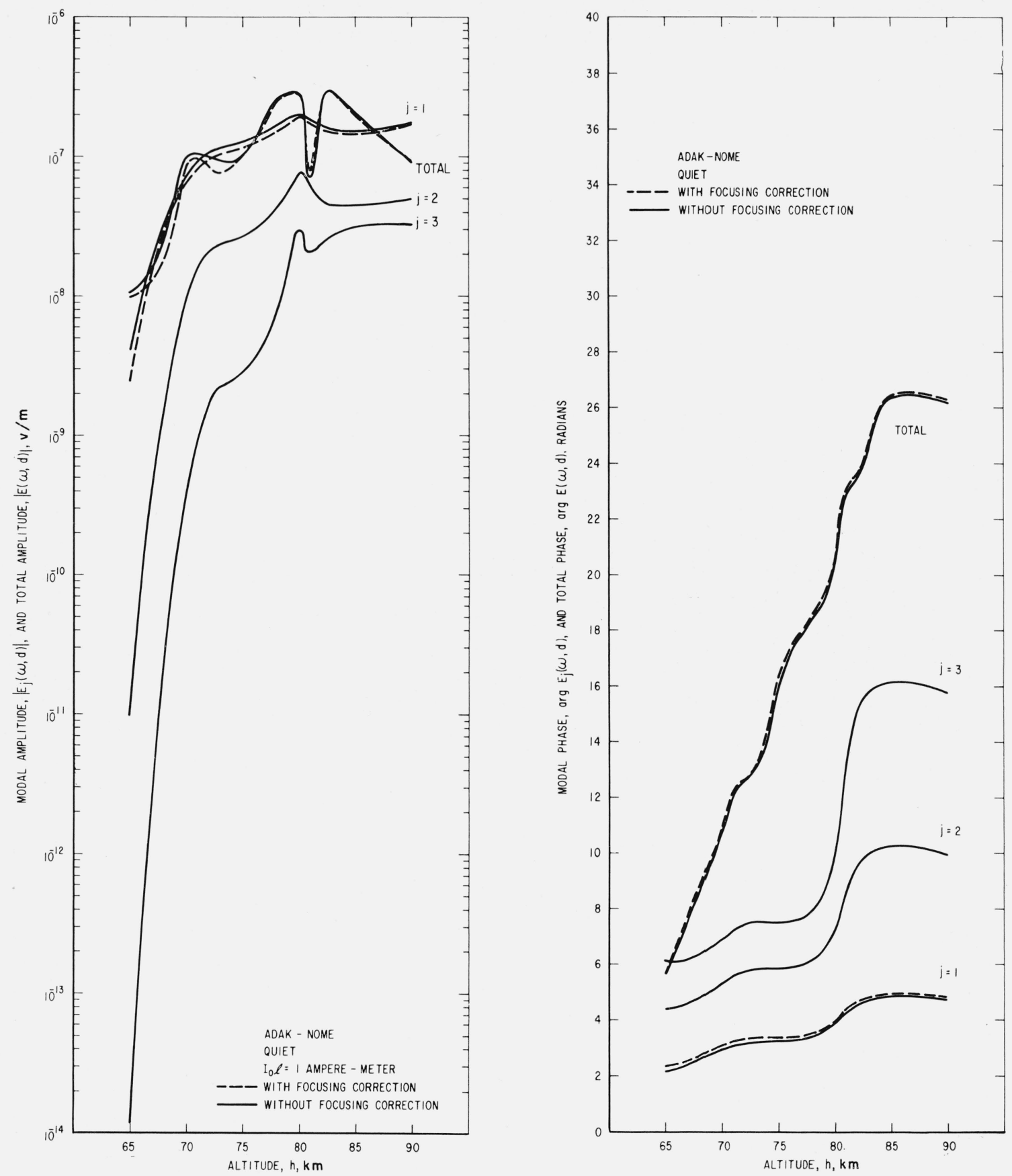

Figure 8. Total theoretical field $\mathrm{E}(\omega, \mathrm{d})$ for various fixed heights, $\mathrm{h}$, of sharply bounded model ionosphere for LF transmissions from Adak to Kodiak, Alaska. 

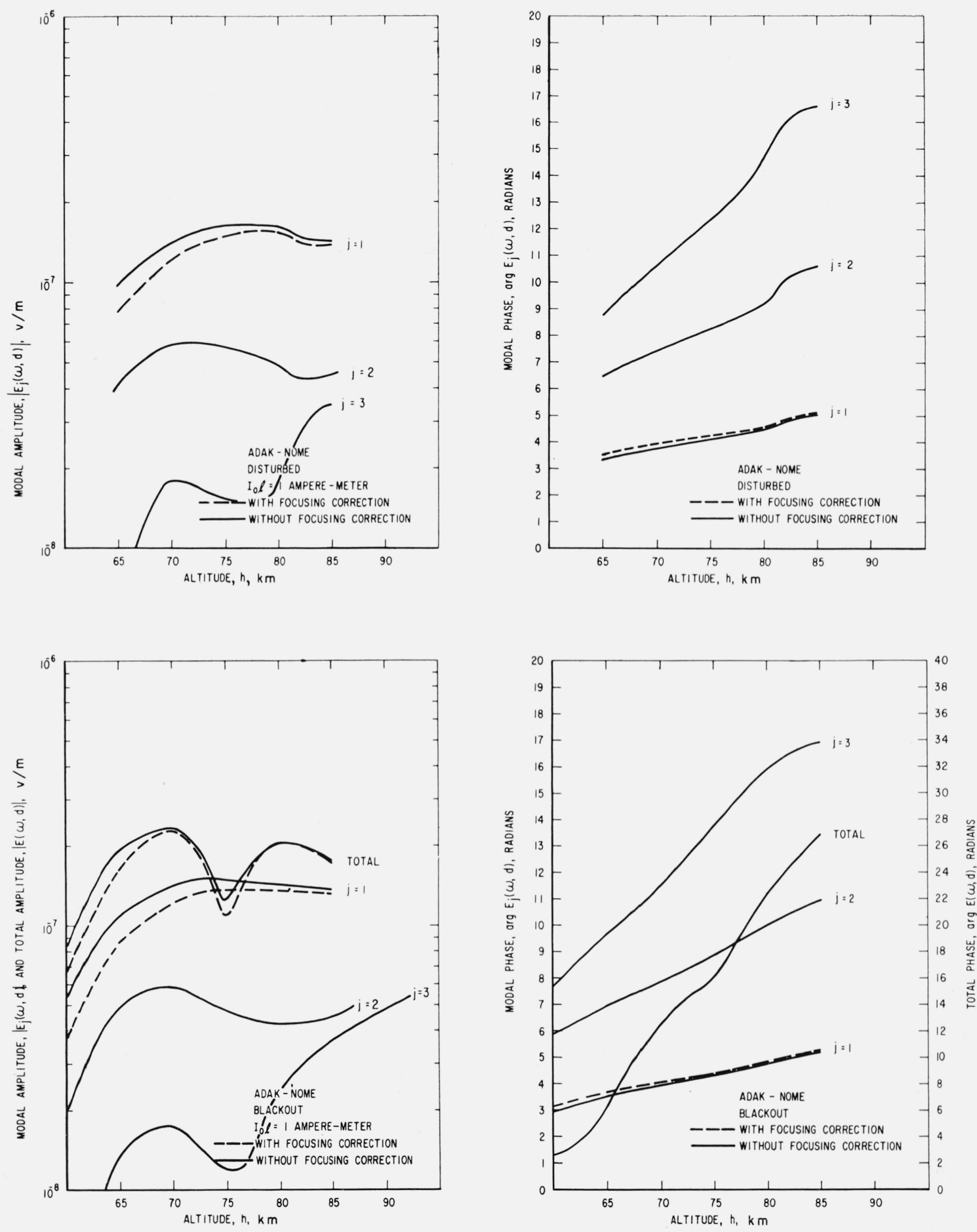

Figure 9. Disturbed-blackout theoretical field E( $\omega, \mathrm{d})$ for various fixed heights, h, of sharply bounded model ionosphere for LF transmissions from Adak to Kodiak, Alaska. 

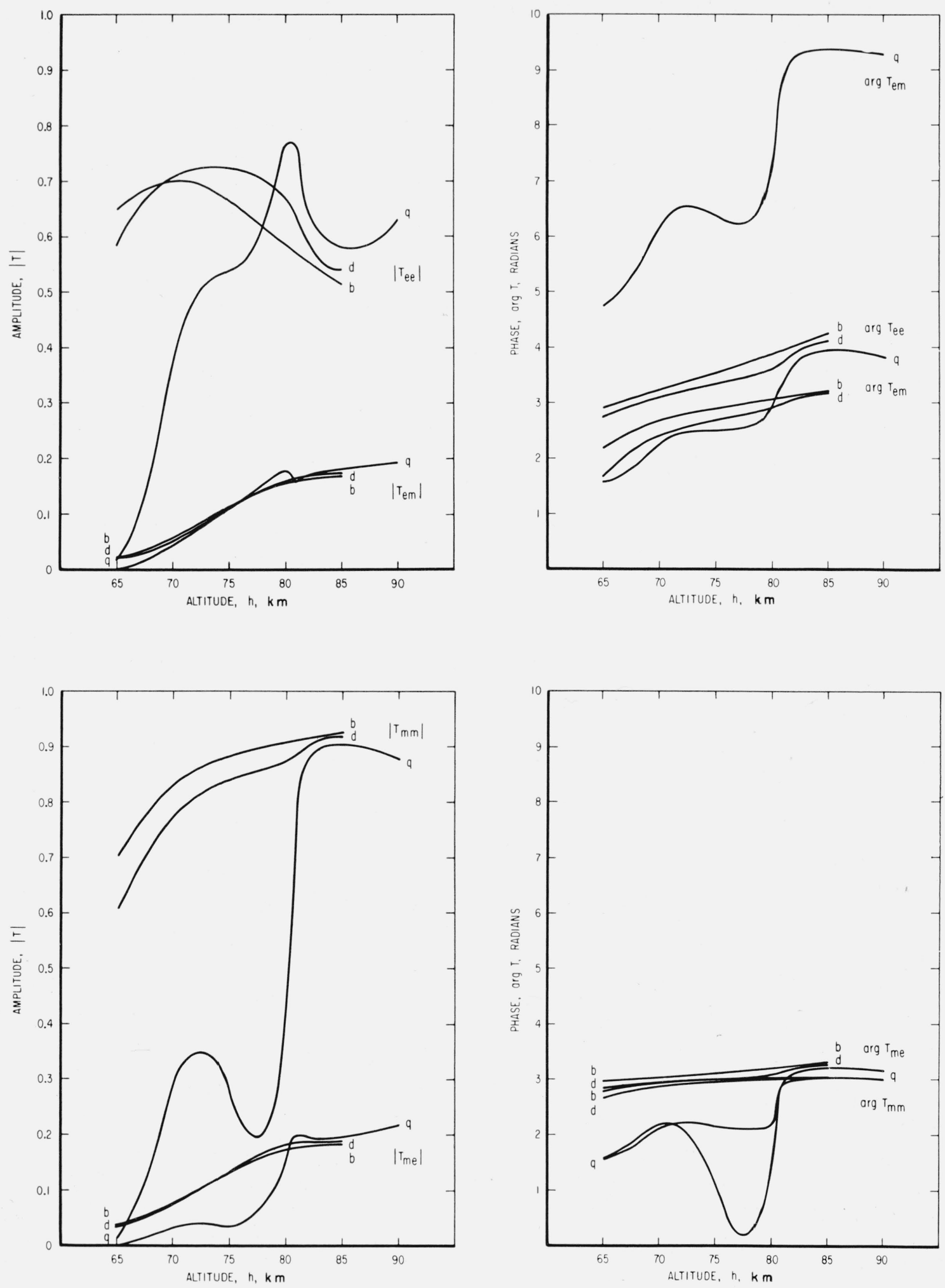

Figure 10. Comparison of quiescent and disturbed-blackout conditions of theoretical reflection coefficient, T, $(\mathrm{j}=1)$, for various fixed heights, $\mathrm{h}$, of sharply bounded model ionosphere for LF transmissions from Adak to Kodiak, Alaska.

$H_{m}=0.5035, \phi_{s}=51.08^{\circ}, I=67.18^{\circ}$ 
In addition to the total field, $E(\omega, d)$, and the modal field, $E_{j}(\omega, d)$, figures 6 to 9 , the reflection coefficients, $T$, (horizontal and vertical polarization; normal and abnormal components), figures 10 to 11, and the transmission data of the ordinary and extraordinary upgoing
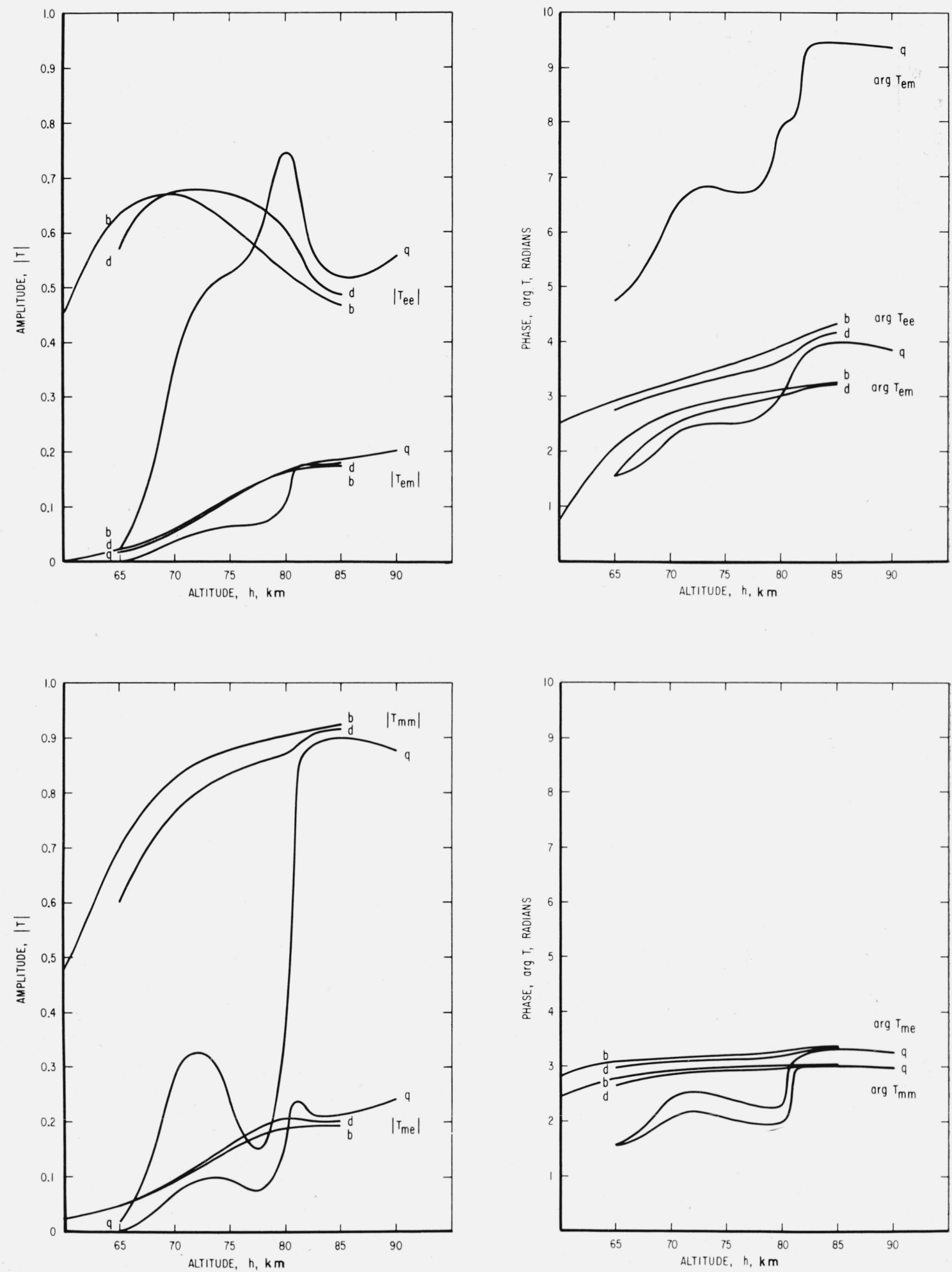

Figure 11. Comparison of quiescent and disturbed-blackout conditions of theoretical reflection coefficient, $\mathrm{T}$, $(\mathrm{j}=1)$, for various fixed heights, $\mathrm{h}$, of sharply bounded model ionosphere for LF transmissions from Adak to Nome, Alasko.

$H_{m}=0.5187, \phi_{\star}=12.27^{\circ}, I=68.68^{\circ}$. 

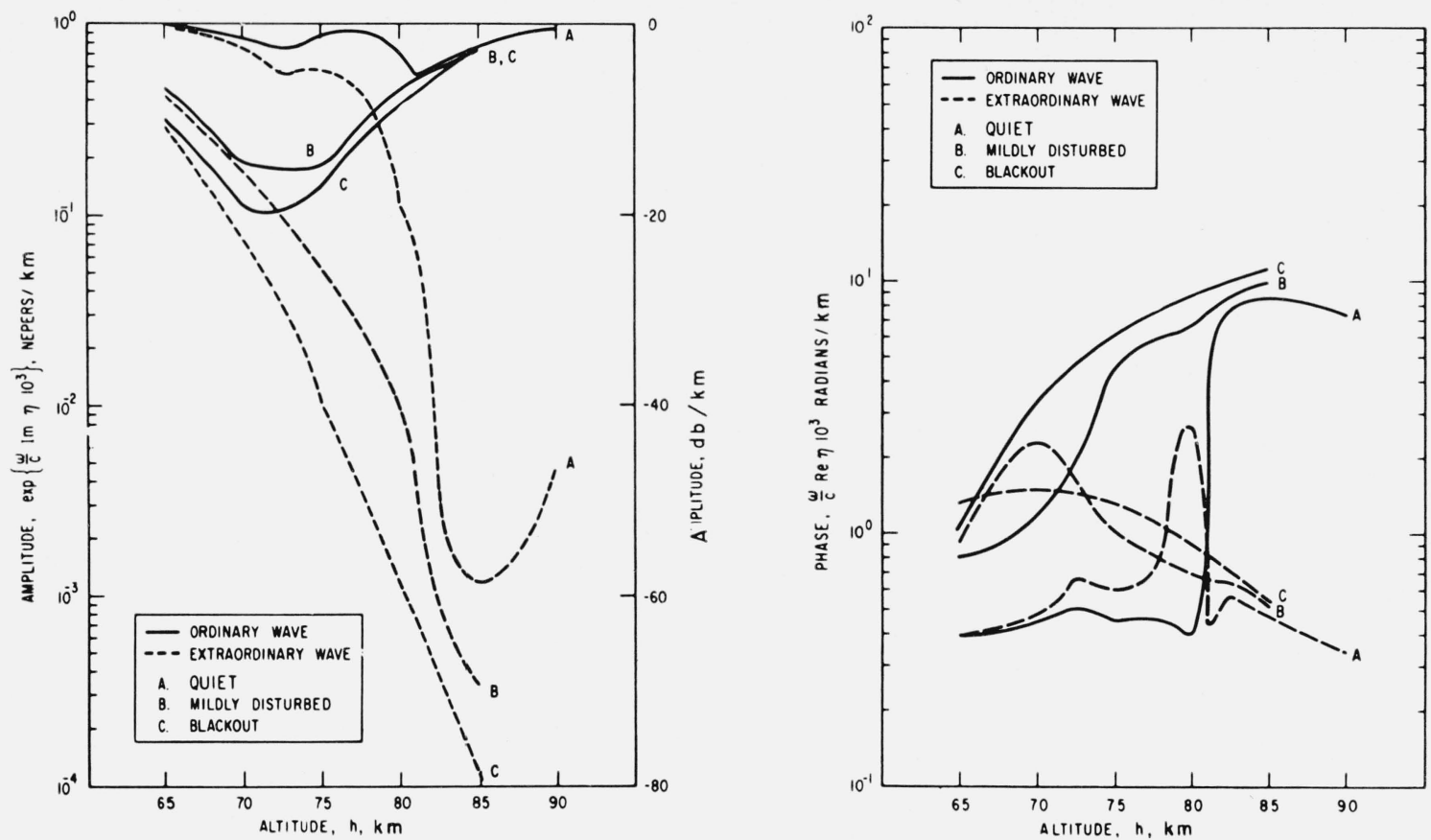

Figure 12. Attcnuation rate and phase lag rate at various emplacement altitudes, $\mathrm{h}$, for upgoing "ordinary" and "extraordinary" waves excited in the model ionosphere by Adak to Kodiak, Alaska transmissions during quiescent and disturbed-blackout conditions.

First time-mode: $H_{m}=0.5035, \phi_{a}=51.08^{\circ}, I=67.18^{\circ}$.
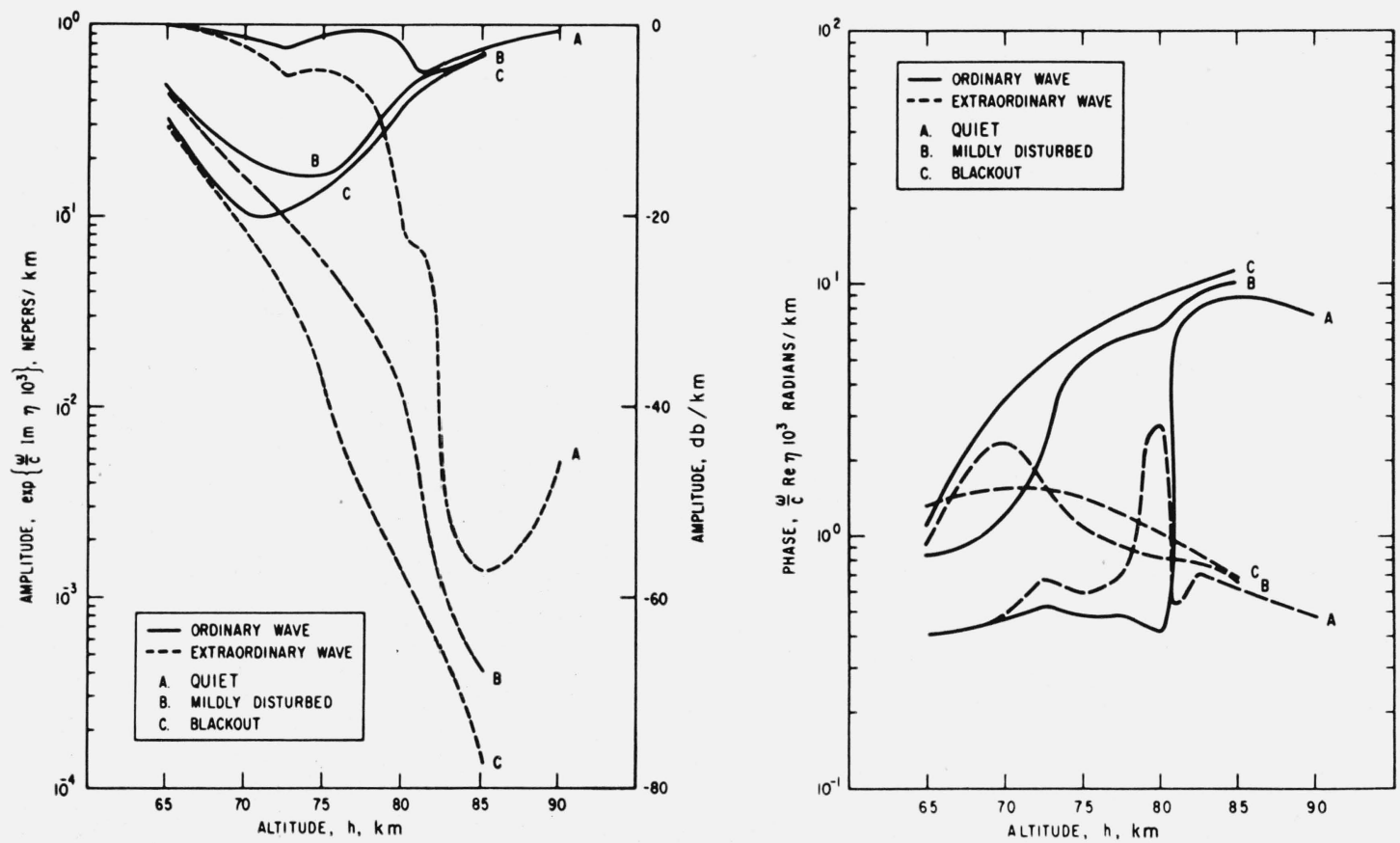

Figure 13. Attenuation rate and phase lag rate at various emplacement altitudes, h, for upgoing "ordinary" and "extraordinary" waves excited in the model ionosphere by Adak to Nome, Alaska transmissions during quiescent and disturbed-blackout conditions.

First time-mode: $H_{m}=0.5187, \phi_{a}=12.27^{\circ}, I=68.68^{\circ}$. 
waves excited in the ionosphere by the reflection process, figures 12,13 , were evaluated. The unabsorbed modal field, $E_{j}(\omega, d) / C_{j}$, and the effective reflection coefficients, $C_{j}$, are separately illustrated, figures 14 and 15 , respectively.

The emplacement height, $h$, of the model ionosphere was deduced by comparison of the computed field strength, $E(\omega, d)$, with the measured value. The corresponding four reflection coefficients, $T_{e e}, T_{e m}, T_{m m}, T_{m e}$, (amplitude and phase) were then evaluated from the theory. The results of this process which were readily scaled from graphs such as illustrated, figures 10 , 11, are presented in table 4, and the reflection coefficients deduced for the first time-mode only are presented.

The higher order time-mode, $j=2,3$, reflection coefficients are obviously quite numerous since a separate set exists for each ionosphere reflecting region. These reflection coefficients are determined by the analysis by reference to the emplacement altitude, $h$, table 5 , deduced from the field, $E(\omega, d)$.

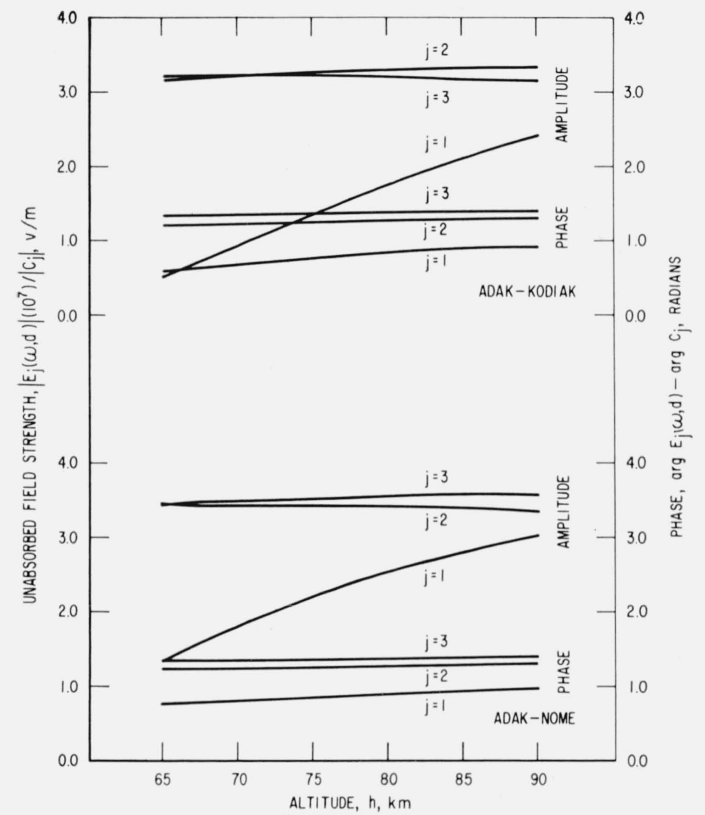

Figure 14. Unabsorbed modal field, $\mathrm{E}_{\mathrm{j}}(\omega, \mathrm{d}) / \mathrm{c}$, at various model ionosphere ciltitude emplacements, h, for Adak to Nome and Kodiak, Alaska transmissions $\mathrm{I}_{0} \mathrm{l}=1$ ampere-meter.

Table 4

Adak-Kodiak (Daytime)

\begin{tabular}{|c|c|c|c|c|c|c|c|c|c|c|c|c|c|c|}
\hline $\begin{array}{l}\% \text { Time } \\
\text { Field }|E| \\
\text { exceeded }\end{array}$ & Season and year & $\begin{array}{l}\text { Observed } \\
|E(\omega, d)|\end{array}$ & $\mathrm{h}$ & $\arg E(\omega, d)$ & ||$E_{1}(\omega, d) \mid$ & $\arg E_{1}(\omega, d)$ & $\left|T_{e e}\right|$ & $\arg T_{e e}$ & $\left|T_{e m}\right|$ & $\arg T_{e m}$ & $\left|T_{m m}\right|$ & $\arg T_{m m}$ & $\left|T_{m e}\right|$ & $\arg T_{m e}$ \\
\hline $\begin{array}{l}10 \ldots \ldots \\
50 \ldots \\
90 \ldots\end{array}$ & Winter 1953-54_. & $\begin{array}{c}\mu v / m \\
33 \\
12 \\
4.8\end{array}$ & $\begin{array}{r}k m \\
69 \\
68 \\
<65\end{array}$ & $\begin{array}{r}\text { Radians } \\
10.4 \\
9.5 \\
<5.0\end{array}$ & $\begin{array}{l}\mu v / m \\
\quad 56 \\
\quad 35 \\
\quad<2.0\end{array}$ & $\begin{array}{r}\text { Radians } \\
2.8 \\
2.6 \\
<2.1\end{array}$ & $\begin{array}{r}0.27 \\
<.19 \\
<.02\end{array}$ & $\begin{array}{r}2.1 \\
2.0 \\
<1.6\end{array}$ & $\begin{array}{l}0.03 \\
.02 \\
0\end{array}$ & $\begin{array}{r}5.8 \\
5.7 \\
<4.8\end{array}$ & $\begin{array}{r}0.23 \\
.16 \\
<.02\end{array}$ & $\begin{array}{r}2.0 \\
1.9 \\
<1.6\end{array}$ & $\begin{array}{l}0.03 \\
.02 \\
0\end{array}$ & $\begin{array}{r}2.1 \\
2.0 \\
<1.6\end{array}$ \\
\hline $\begin{array}{l}10 \\
50 \\
90\end{array}$ & Autumn 1954 & $\begin{array}{l}20 \\
7.1 \\
2.6\end{array}$ & $\begin{array}{r}69 \\
<65 \\
<65\end{array}$ & $\begin{array}{l}10.4 \\
<5.0 \\
<5.0\end{array}$ & $\begin{array}{l}56 \\
<2.0 \\
<2.0\end{array}$ & $\begin{array}{r}2.8 \\
<2.1 \\
<2.1\end{array}$ & $\begin{array}{r}.27 \\
<.02 \\
<.02\end{array}$ & $\begin{array}{r}2.1 \\
<1.6 \\
<1.6\end{array}$ & $\begin{array}{l}0^{.03} \\
0\end{array}$ & $\begin{array}{r}5.8 \\
<4.8 \\
<4.8\end{array}$ & $\begin{array}{r}.23 \\
<.02 \\
<.02\end{array}$ & $\begin{array}{r}2.0 \\
<1.6 \\
<1.6\end{array}$ & $\begin{array}{l}.03 \\
0\end{array}$ & $\begin{array}{r}2.1 \\
<1.6 \\
<1.6\end{array}$ \\
\hline
\end{tabular}

Adak-Nome (Daytime)

\begin{tabular}{|c|c|c|c|c|c|c|c|c|c|c|c|c|c|c|}
\hline $\begin{array}{l}10 \\
50 \\
90\end{array}$ & Winter $1953-54$ & $\begin{array}{r}124 \\
56 \\
22\end{array}$ & $\begin{array}{l}69 \\
68 \\
65.5\end{array}$ & $\begin{array}{l}9.8 \\
9.0 \\
6.4\end{array}$ & $\begin{array}{c}94 \\
60 \\
9.0\end{array}$ & $\begin{array}{l}3.0 \\
2.7 \\
2.4\end{array}$ & $\begin{array}{r}0.29 \\
.18 \\
.04\end{array}$ & $\begin{array}{l}2.1 \\
1.9 \\
1.6\end{array}$ & $\begin{array}{l}0.03 \\
.02 \\
.01\end{array}$ & $\begin{array}{l}\text { 5. } 95 \\
\text { 5. } 55 \\
4.8\end{array}$ & $\begin{array}{l}0.23 \\
.15 \\
.035\end{array}$ & $\begin{array}{l}\text { 1. } 95 \\
1.8 \\
1.6\end{array}$ & $\begin{array}{l}0.055 \\
<.04 \\
<.01\end{array}$ & $\begin{array}{l}\text { 2. } 25 \\
2.0 \\
1.6\end{array}$ \\
\hline $\begin{array}{l}10 \\
50 \\
90\end{array}$ & Autumn 1954 & $\begin{array}{l}64 \\
28 \\
11\end{array}$ & $\begin{array}{r}68.5 \\
6.5 \\
<65\end{array}$ & $\begin{array}{r}9.3 \\
7.4 \\
<5.7\end{array}$ & $\begin{array}{l}70 \\
22 \\
<5.0\end{array}$ & $\begin{array}{r}2.8 \\
2.5 \\
<2.3\end{array}$ & $\begin{array}{r}.22 \\
.08 \\
<.02\end{array}$ & $\begin{array}{r}1.95 \\
1.65 \\
<1.55\end{array}$ & $\begin{array}{l}.025 \\
.01\end{array}$ & $\begin{array}{r}5.7 \\
5.0 \\
<4.75\end{array}$ & $\begin{array}{r}.18 \\
<.065 \\
<.02\end{array}$ & $\begin{array}{rl} & 1.9 \\
1 & 1.65 \\
< & 1.6\end{array}$ & $\begin{array}{l}.045 \\
.015 \\
0\end{array}$ & $\begin{aligned} & 2.1 \\
& 1.75 \\
< & 1.6\end{aligned}$ \\
\hline $\begin{array}{l}10 \\
50 \\
90\end{array}$ & Spring $1954 \ldots$ & $\begin{array}{l}34 \\
19 \\
10\end{array}$ & $\begin{array}{r}67 \\
<65 \\
<65\end{array}$ & $\begin{array}{r}7.8 \\
<5.7 \\
<5.7\end{array}$ & $\begin{array}{l}36 \\
<5.0 \\
<5.0\end{array}$ & $\begin{array}{r}2.6 \\
<2.3 \\
<2.3\end{array}$ & $\begin{array}{r}\quad .11 \\
<.02 \\
<.02\end{array}$ & $\begin{array}{r}1.75 \\
<1.55 \\
<1.55\end{array}$ & $\begin{array}{l}.015 \\
0\end{array}$ & $\begin{aligned} & 5.2 \\
< & 4.75 \\
< & 4.75\end{aligned}$ & $\begin{array}{r}.09 \\
<.02 \\
<.02\end{array}$ & $\begin{array}{r}1.7 \\
<1.6 \\
<1.6\end{array}$ & $\begin{array}{l}.02 \\
0 \\
0\end{array}$ & $\begin{array}{r}1.8 \\
<1.6 \\
<1.6\end{array}$ \\
\hline
\end{tabular}



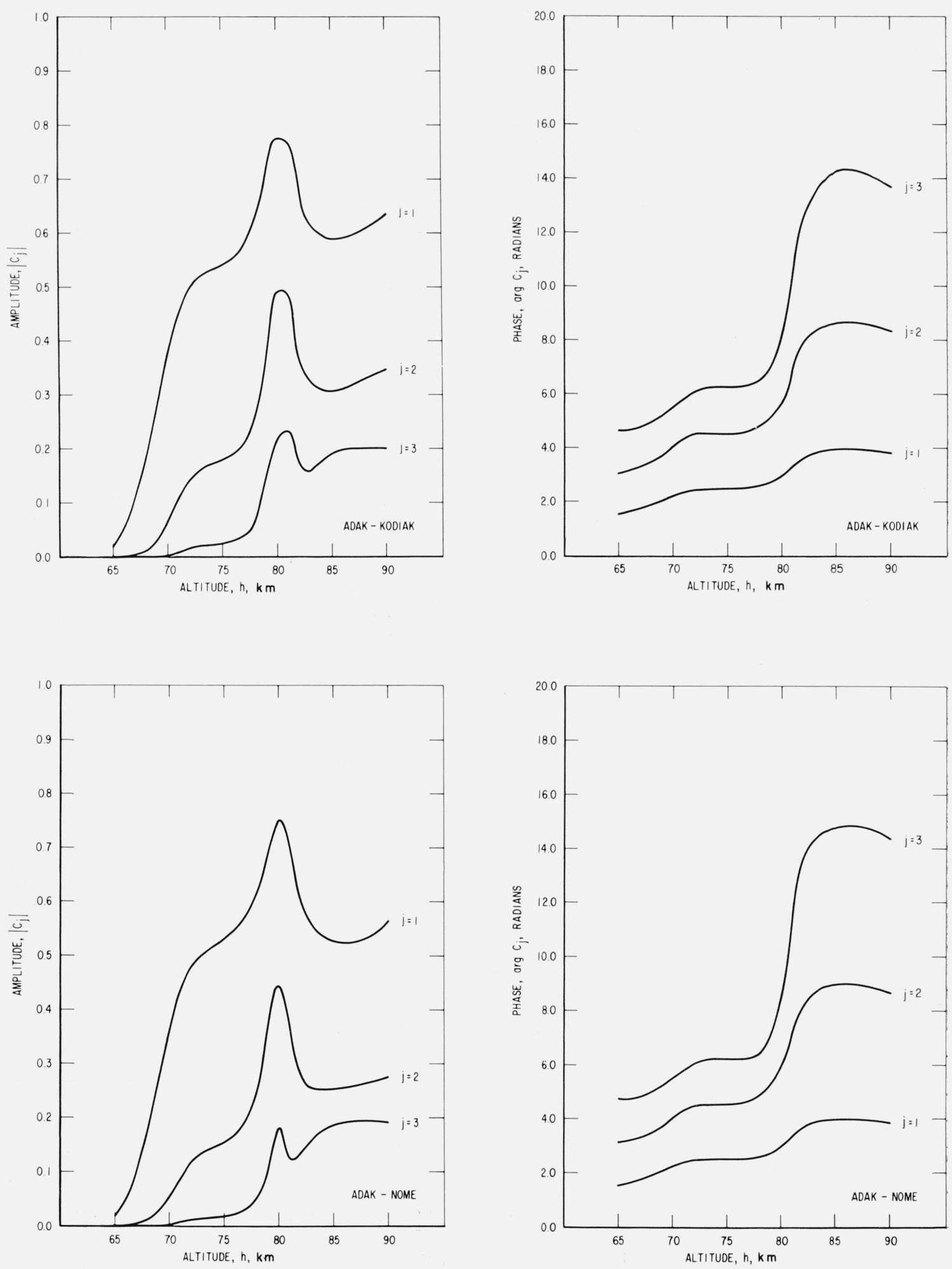

Figure 15. Effective reflection coefficient, $\mathrm{c}_{\mathrm{j}}$, for Adak to Nome and Kodiak, Alaska, transmissions under quiescent ionosphere conditions. 
TABLE 5

\begin{tabular}{|c|c|c|c|c|c|}
\hline Condition & Mode & $N$ & $h$ & $|E(\omega, d)|$ & $\arg E$ \\
\hline & $\begin{array}{l}\text { Total } \\
\text { Total } \\
j=1 \\
\text { Total } \\
j=1\end{array}$ & $\begin{array}{r}\mathrm{El} / \mathrm{cm}^{3} \\
10 \\
1000 \\
10 \\
10 \\
10\end{array}$ & $\begin{array}{r}k m \\
55 \\
60 \\
55 \\
65 \\
65\end{array}$ & $\begin{array}{c}v / m \\
7.59\left(10^{-9}\right) \\
6.60\left(10^{-8}\right) \\
1.18\left(10^{-10}\right) \\
9.77\left(10^{-9}\right) \\
2.42\left(10^{-9}\right)\end{array}$ & $\begin{array}{r}\text { radians } \\
5.54 \\
2.84 \\
2.10 \\
5.66 \\
2.33\end{array}$ \\
\hline
\end{tabular}

It is interesting to note emplacement altitudes, $h$, less than $65 \mathrm{~km}$ under quiescent conditions. Indeed, the highest altitude for these daytime values was $69 \mathrm{~km}$ (winter 1954). A good nominal day time emplacement altitude is $67.5 \mathrm{~km}$. The low value $(|T|<0.1)$ reflection coefficients are also quite interesting. Note the highest value, $|T| \sim 0.27$. Note also, the median value at Nome (1954 equinox), $\left|T_{e e}\right|=0.08$. A low value $|T|<0.1$, and "black", $|T| \sim 0$ appearance of the ionosphere indicates a low level absorbing region in the lower ionosphere at grazing incidence. A region of low electron density, $N=10-100 \mathrm{El} / \mathrm{cm}^{3}$, is indicated by the model employed, figure 4 . The transmission into such a region at grazing incidence, $\phi_{i} \sim 80^{\circ}$, figures 11,12 , indicates almost complete absorption of both the "ordinary" and the "extraordinary" rays if a "virtual height," $h+\Delta h$, is assumed of the order of $70 \mathrm{~km}$. The transmission curves, figures 11,12 , demonstrate that the "extraordinary" ray is very highly attenuated such that it is necessary to consider only the "ordinary" ray. Assuming $1 \mathrm{db} / \mathrm{km}$, for example, figures 11,12 , and a virtual height, $h+\Delta h$, of $70 \mathrm{~km}$, noting that appreciable attenuation rate begins at $65 \mathrm{~km}$, the total attenuation can be estimated; total decibels $\sim 2 \Delta h / \cos \phi_{i} \sim 57 \mathrm{db}$. This, of course, neglects a reflection absorption at the $70 \mathrm{~km}$ virtual height plus the transmission absorption back into the region below the ionosphere. The values, $\Delta h$, can be decreased and a corresponding decrease in the attenuation noted. But a repetition of the process leads to the interesting conclusion that most of the ray reflection must occur in a fraction of a kilometer, and, hence, the sharply bounded model can be reasonably applied under these conditions to predict the LF field, $E(\omega, d)$. A similar examination of the second and third time-modes leads to an almost similar reflecting region since the angle of incidence, $\phi_{i}$, figure 2 , does not change rapidly until the distance, $d / j$, is sufficiently short. It is, nevertheless, conceivable that the amplitude of the skywave reflections, $j=4,5,6$, . . at shorter distances could become quite large as a result of reflection from a high level "virtual height," $h+\Delta h=70$ to $85 \mathrm{~km}$. Under these conditions, however, the sharply bounded model would not be valid and it would be necessary to develop theoretical techniques for a diffusely bounded model ionosphere.

Information on the lower ionosphere $N(h)$ profile during nighttime conditions is quite sparse and hence the theoretician can only speculate on its nature. However, under certain reasonable assumptions, a possible explanation of the increase in field strength experienced at night may be deduced from the daytime model ionosphere employed.

Despite the seeming "evaporation" of the lower regions of the ionosphere at night with a corresponding abrupt increase of the electron density to a large finite value, it seems reasonable to assume that this abrupt increase does not occur within $\lambda / 10$ or $0.22 \mathrm{~km}$ at $135.6 \mathrm{kc} / \mathrm{s}$. This makes it possible to utilize the present sharply bounded model ionosphere, if it is emplaced at a higher level. Recent work [Ellyett and Watts, 1959] indicates a height of 80 to $85 \mathrm{~km}$ is not unreasonable.

Since the change of the angle of incidence, $\phi_{i}$, figure 2 , with ionosphere height, $h$, is not great at this range, we may neglect its effect on the field strength, figures 6 to 9 , and the effective reflection coefficients, figure 15. The only factor changed, therefore, is the unabsorbed field, figure 14. It therefore seems reasonable to expect the first time mode, $\left|E_{1}(\omega, d)\right|$, to increase on the order of at least twice, whereas, reference to the arctic data and figure 16, "Battle Lake data" (to be discussed below), indicates an increase of perhaps 4 to 10 times. This could easily be explained by a slight change of slope in the $N(h)$ profile employed as evidenced by the steep slope of the $C_{1}$ curves $(j=1)$, figure 15 , in the region involved. On this basis, it is reasonable to expect a nighttime reflection coefficient, $|T| \sim 0.3,0.4$. Indeed, at temperate latitude, these values are confirmed [Ross, 1959]. 
It is not surprising that a large phase change could be expected during the sunset-sunrise transition periods, figures 6 and 8 . Indeed, such phase changes were described at $100 \mathrm{kc} / \mathrm{s}$ by Doherty [1957], while operating the Loran-C on the first time-mode of the skywave.

The behavior of the LF propagation during disturbed and blackout conditions which are especially frequent in the arctic-auroral region is not quite so clear. Figures 7 and 9 illustrate disturbed-blackout conditions based on the geophysical measurements of electron density profiles, $N(h)$, of the lower ionosphere, figure 4 . The corresponding reflection coefficients, figures 10, 11, and the transmission of upgoing ordinary and extraordinary waves excited by the reflection process are also illustrated, figures 12, 13. The disturbance of the earth's magnetic field during extreme blackout conditions is negligible since the total field, $H_{m} \sim 0.5$ gauss and the fluctuations are of the order of 0.001 gauss [Chapman, 1940]. The most significant change in the propagation is caused by the drastic change in the electron density profile, $N(h)$, figure 4. Unfortunately, the shape of the lower levels, $<60 \mathrm{~km}$, of the "blackout" $N(h)$ profile is unknown. Since the analysis under quiescent conditions indicates lowelectron density reflections, the curve, figure 4, was extrapclated, and the corresponding field, $E(\omega, d)$, calculated for Adak to Nome transmission. The results are tabulated in table 5 .

Note the $j=1$ mode for a region of $N=10 \mathrm{El} / \mathrm{cm}^{3}$ has undergone a $26 \mathrm{db}$ decrease and the total field is therefore almost entirely groundwave. Appreciable as the decrease is, it is still well within the range of observations of arctic data. Notice, figure 16 "Battle Lake data" (to be discussed below), that the range of observations in temperate latitudes is approximately $18 \mathrm{db}$. The additional fluctuation may then, reasonably, be attributed to the change in electron density of the extreme lower ionosphere. If this change were to be so abrupt as to reach $N=1000 \mathrm{El} / \mathrm{cm}^{3}$ in, say, $\lambda / 10 \mathrm{~km}$, the field strength would show a considerable increase, instead of decrease. It is reasonable to expect that a more realistic value of somewhat less than $N=1000 \mathrm{El} / \mathrm{cm}^{2}$ would also produce an increase in the received field strength. The shape of the $N(h)$ profile, thus, becomes quite important.

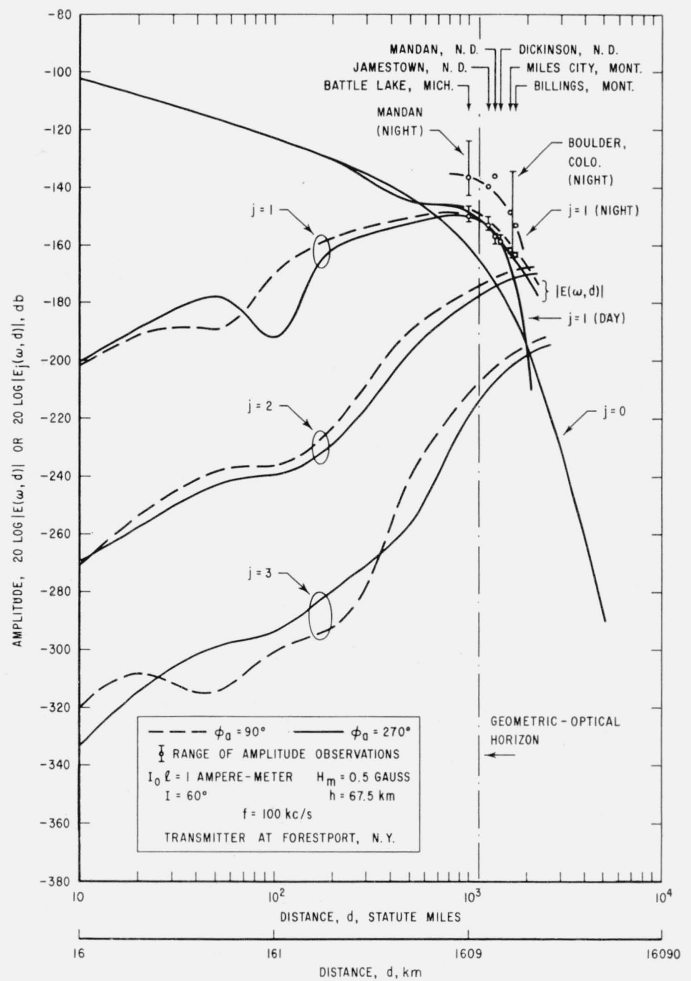

Figure 16. Amplitude of theoretical total field $|\mathrm{E}(\omega, \mathrm{d})|$ as a function of distance, $\mathrm{d}$, from the source illustrating a comparison of experimental pulse amplatude measurements with theoretical first time-mode in the diffraction zone beyond the geometrical-optical horizon.

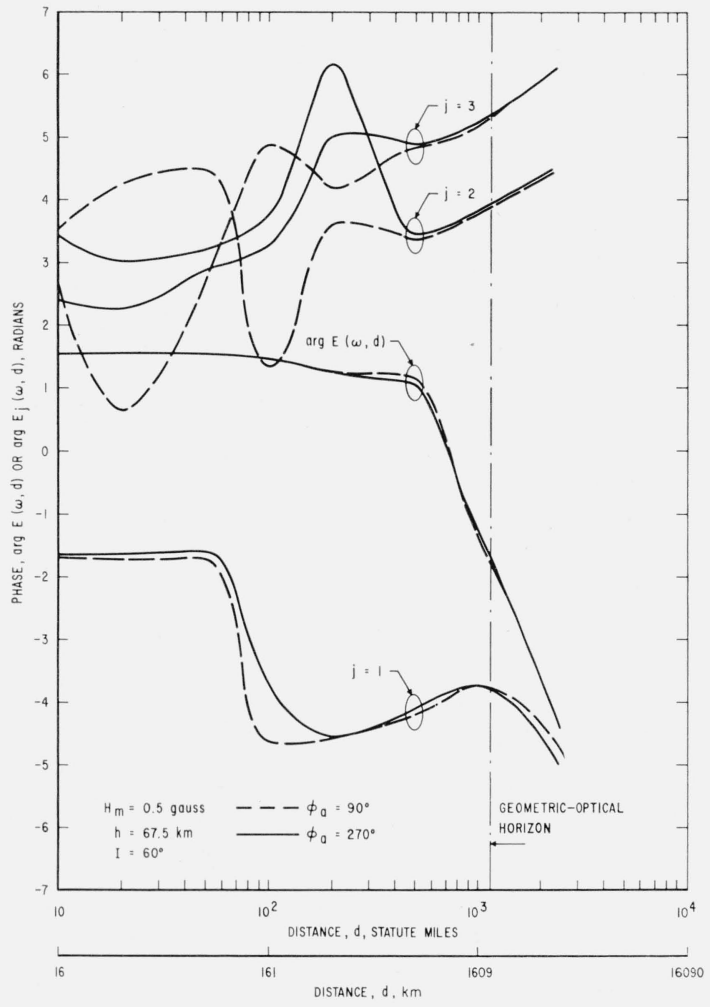

Figure 17. Phase of theoretical field arg $\mathrm{E}(\omega, \mathrm{d})$ as a function of distance. 
The calculation of the amplitude and phase of the total field, $E(\omega, d)$ as a function of distance is illustrated in figures 16 and 17. The corresponding reflection coefficient $T_{e e}$ (vertical polarization, normal component) is illustrated in figure 18.

Amplitude measurements ${ }^{6}$ during the day which illustrate the diffraction of the first time-mode $(j=1)$ near and beyond the geometric-optical horizon are illustrated in figure 16 . The agreement with the theoretical curve $j=1$ appears to be quite close except at the range of 1,800 miles. It is interesting to note the apparent decrease in the range of amplitude observations in the daytime, indicating greater amplitude stability with range in the diffraction zone.

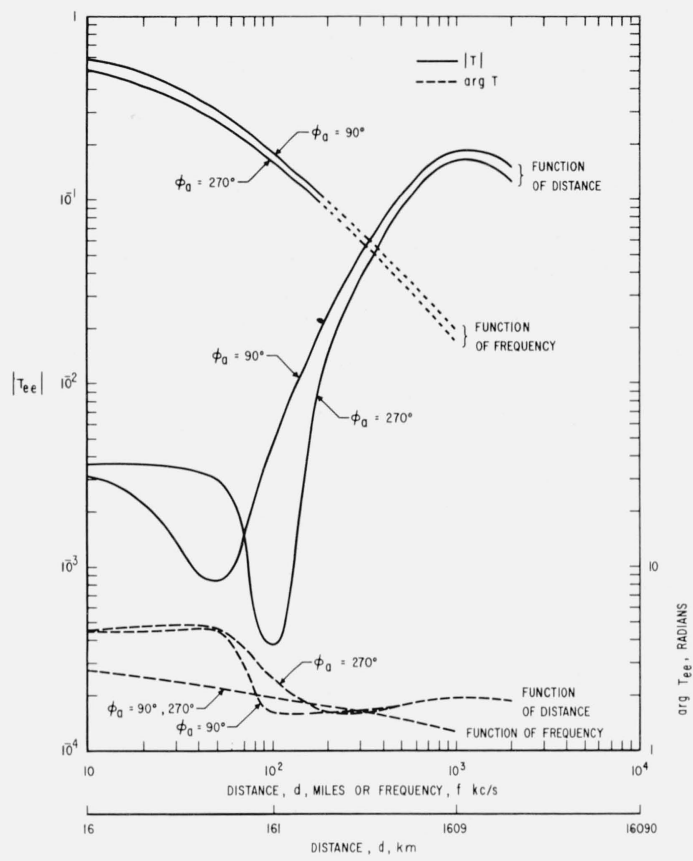

Figure 18. Amplitude and phase of the normal component reflection coefficient $\mathrm{T}_{\mathrm{ee}}$ (vertical polarization) as a function of distance and frequency for east-towest $\phi_{\mathrm{a}}=270^{\circ}$ and west-to-east $\phi_{\mathrm{a}}=90^{\circ}$ propagation.

\section{Conclusion}

The analysis of these data demonstrates the application of propagation theory together with a suitable model for the ionosphere to the prediction of LF phenomena. The precision of the model for the case of transmission via the ionosphere at or close to grazing incidence is considered to be adequate upon considering the state of knowledge of the many parameters which influence such propagation. Nevertheless, the absence of an abundance of specific information does not deter the author from certain general conclusions which can be made as a result of this research.

At oblique incidence on the ionosphere, a condition which is certainly met under most practical situations, the reflection of LF waves during the daytime occurs in a region of very low electron density and high absorption, with corresponding low values of reflection coefficients, $|T|<0.1$. The dominant skywave time-mode is, in general, the first; however, the second, third and higher order time-modes may offer appreciable contribution to the total field as the angle of incidence decreases as a result of reflection from higher levels and shorter transit distance in the ionized medium.

Periods of ionospheric disturbance (blackout) can produce a decrease in the field as a result of a reduction in the amplitude of the ionospheric time-modes. However, it is equally possible for the skywave mode to be incremented. This phenomenon is dependent upon the slope of

${ }^{6}$ From the author's personal notes on the 1953-1954 testing of the Loran-C (Cytac) System. 
the electron density-altitude profile, $N(h) h$. However, if ordinary communication is an engineering objective, LF seem to be quite reliable since the characteristic high absorption of HF waves does not appear to exist.

Since the writing of this paper the extensive theoretical work of Barron [1961] and the extensive experimental and engineering work of Belrose et al., [1959] have come to the attention of the author. It is interesting to note quite good agreement, figure 18 , between the reflection coefficients deduced from the sharply bounded model presented in this paper and those presented as a result of Barron's full wave computations. Barron's data does, however, indicate, as might be expected, higher attenuation at the higher frequencies $(>150 \mathrm{kc} / \mathrm{s})$.

It should be noted in conclusion that the adequacy of the sharply bounded model is subject to severe limitations, especially at the higher frequencies and the results of this paper suggest also the introduction into this geometric optical analysis of more rigorous or flexible models for the reflection coefficient which would treat a more diffuse ionosphere lower boundary.

\section{References}

Ballantine, S., On the radiation resistance of a simple vertical antenna at wave lengths below the fundamental, Proc. IRE 12, 823-829 (Dec. 1924).

Barron, D. W., The numerical solution of differential equations governing the reflexion of long radio waves from the ionosphere, IV, Proc. Roy. Soc. 260, Ser. A, No. 302, 393-408 (March 1961).

Belrose, J. S., W. L. Hutton, C. A. McKerrow, and R. S. Thain, The engineering of communication systems for low radio frequencies, Proc. IRE 47, No. 5, pt. 1, 661-680 (May 1959).

Bickel, J. E., A method for obtaining LF oblique incidence reflection coefficient and its application to 135.6 ke data in the Alaska area, J. Geophys. Research 62, No. 3, 373-381 (Sept. 1957).

Bremmer, H., Terrestrial radio waves-theory of propagation (Elsevier Publishing Co., New York, N.Y., 1949).

Chapman, S., and J. Bartels, Geomagnetism, Vol. I (Oxford at the Clarendon Press, 1940).

Crompton, R. W., L. G. H. Huxley, and D. J. Sutton, Experimental studies of the motions of slow electrons in air with applications to the ionosphere, Proc. Roy. Soc. London 218, Ser. A, 507-519 (July 1953).

Davis, P., and P. Rabinowitz, Abscissas and weights for Gaussian quadratures of high order, J. Research NBS 56, 35-37 (Jan. 1956).

Doherty, R. H., private communication (1957).

Ellyett, C., and J. M. Watts, Stratification in the lower ionosphere, J. Research NBS 63D (Radio Prop.). No. 2, 117-134 (Sept.-Oct. 1959).

Fejer, J. A., The interaction of pulsed radio waves in the ionosphere, J. Atmospheric and Terrest. Phys. $\boldsymbol{7}$, 322-332 (Dec. 1955).

Gardner, F. F., and J. L. Pawsey, Study of the ionospheric D-region using partial reflections, J. Atmospheric and Terrest. Phys. 3, 321-344 (July 1953).

Johler, J. R., Magneto-ionic propagation phenomena in low- and very low-radiofrequency waves reflected by the ionosphere, J. Research NBS 65D, (Radio Prop.), No. 1, 53-61 (Jan.-Feb. 1961).

Johler, J. R., W. J. Kellar, and L. C. Walters, Phase of the low radiofrequency ground wave, NBS Cire. 573, U.S. Government Printing Office, Washington 25, D.C. (June 26, 1956).

Johler, J. R., and L. C. Walters, Propagation of a ground wave pulse around a finitely conducting spherical earth from a damped sinusoidal source current, IRE Trans. on Antennas and Propagation AP-y, No. 1, 1-10 (Jan. 1959).

Johler, J. R., and L. C. Walters, On the theory of reflection of low- and very low-radio-frequency waves from the ionosphere, J. Research NBS 64D (Radio Prop.), No. 3, 269-285 (May-June 1960).

Johler, J. R., L. C. Walters, and J. D. Harper, Jr., Low- and very low-radiofrequency model ionosphere reflection coefficients, NBS Tech. Note 69 (PB161570), U.S. Dept. of Commerce, Office of Technical Services, Washington 25, D.C. (July 1, 1960).

Johler, J. R., L. C. Walters, and C. M. Lilley, Low- and very low-radiofrequency tables of ground wave parameters for the spherical earth theory: The roots of Riccati's differential equation, NBS Tech. Note 7 (PB 151366), U.S. Dept. of Commerce, Office of Technical Services, Washington 25, D.C. (Feb. 1, 1959).

Johler, J. R., L. C. Walters, and C. M. Lilley, Amplitude and phase of the low- and very low-radiofrequency ground wave, NBS Tech. Note 60 (PB161561), U.S. Dept. of Commerce, Office of Technical Services, Washington 25, D.C. (June 1, 1960).

Lorentz, H. A., The theory of electrons and its applications to the phenomena of light and radiant heat (G. E. Stechert and Co., New York, N.Y., 1906, 1923).

Magnetic Chart $1706 \mathrm{~N}$, The variation of the compass for the year 1955 North Polar area, U.S. Navy Hydrographic Office, Washington, D.C. (1946); 3rd edition (1954). 
Magnetic Chart $1700 \mathrm{~N}$, The magnetic inclination or dip for the year 1955 North Polar area, U.S. Navy Hydrographic Office, Washington, D.C. (1946); 3rd edition (1954).

Magnetic Chart 1703 N, The total intensity of the Earth's magnetic field for the year 1955 North Polar area, U.S. Navy Hydrographic Office, Washington, D.C., (1947); 2nd edition (1954).

Millington, G., Ground-wave propagation across a land/sea boundary, Nature 164, 114-115 (July 1949); Nature 163, p. 128 (June 1949).

Millington, G., Ground-wave propagation over an inhomogeneous smooth earth, Proc. IRE 96, pt III, 53-63 (1949).

Nicolet, M., Aeronomic conditions in the mesosphere and lower ionosphere, Science Report No. 102, Pennsylvania State University, University Park, Pennsylvania (April 1958).

Rabinowitz, P., and G. Weiss, Tables of abscissas and weights for numerical evaluation of integrals of the form $\int_{0}^{\infty} e^{-x} x^{n} f(x) d x$

Mathematical Tables and Other Aids to Computation, Vol. 13, No. 68, p. 285 (Oct. 1959).

Ratcliffe, J. A., Ionizations and drift in the ionosphere, J. Geophys. Research 64, No. 12, 2102-2111 (Dec. 1959).

Ross, J. M., Propagation field test, Appendix D (uncl.), Navigation, guidance and control system for drone aircraft, 6th Quarterly Progress Report to U.S. Army Signal Research and Development Laboratory, Ft. Monmouth, N.J. (Sept.-Nov. 1959), Contract No. DA 36-039 SC-78020, Motorola, Inc., Scottsdale, Arizona.

Seddon, J. C., and J. E. Jackson, Rocket arctic ionospheric measurements, IGY Rocket Report Series, No. 1, pp. 140-148 (July 1958).

Wait, J. R., Diffractive corrections to the geometrical optics of low frequency propagation, Electromagnetic wave propagation, pp. 87-101 (Academic Press, New York, N.Y., 1960a).

Wait, J. R., private communication, eq. (37), (1960b).

Wait, J. R., A diffraction theory for LF sky wave propagation, J. Geophys. Research 66, No. 6, 1713-1730 (June 1961).

Wait, J. R., and A. M. Conda, Pattern of an antenna on a curved lossy surface, IRE Trans. on Antennas and Propagation AP-6, No. 4, 348-359 (October 1958).

Watt, A. D., E. L. Maxwell, and E. H. Whelen, Low-frequency propagation paths in artic areas, J. Research NBS 63D (Radio Prop.), No. 1, 99-112 (July-Aug. 1959).

Waynick, A. H., The present state of knowledge concerning the lower ionosphere, Proc. IRE 45, No. 6, 741749 (June 1957).

(Paper 65D5-156) 


\section{Publications of the staff of the National Bureau of Standards*}

\section{Selected Abstracts}

\begin{abstract}
Mean electron density variations of the quiet jonosphere 3May 1959, J. W. Wright, L. R. Wescott, and D. J. Brown, NBS Tech. Note 40-3 (PB151399-3) (1960) \$1.50.

The CRPL has initiated a program for large-scale computation of electron density profiles from ionospheric vertical soundings. Scaling is performed at field stations permitting computation of hourly profiles at the Central Laboratory. These profiles are combined to form hourly mean quiet profiles for each station and month. The results of this program for the month of May are illustrated graphically. This report is the third of a series illustrating the electron density variations in the mean quiet ionosphere between latitudes $15^{\circ} \mathrm{N}$ and $50^{\circ} \mathrm{N}$ along the $75^{\circ} \mathrm{W}$ meridian.
\end{abstract}

On the nature of equatorial spread $\boldsymbol{- F}, \mathrm{R}$. Cohen and $\mathrm{K}$. L Bowles, J. Geophys. Research 66, No. 4, 1081-1106 (April 1961).

Ionospheric propagation via scattering from the $F$ region was sought at $50 \mathrm{Mc} / \mathrm{s}$ over a transequatorial path (with midpoint near Huancayo, Peru) employing a $2580-\mathrm{km}$ transmitter-receiver separation. Propagation via $F$ scatter was present over this path about 10 per cent of the time, though only at night. A condition closely related to the occurrence of $F$ scatter was the presence of equatorial spread- $F$ configurations on the Huancayo ionograms. The height of the propagation medium supporting this $F$ scatter was usually identifiable with the lowest height of the associated equatorial spread $F$ on the ionograms. On the basis of an interpretation of experimental results, equatorial spread $F$ is shown to arise from scattering by relatively thin sheets of irregularities in electron density which occur at the bottom of the $F$ layer or as much as $100 \mathrm{~km}$ lower. The thickness of these patches is estimated at the order of $50 \mathrm{~km}$. The scattering irregularities comprising these patches are found to be elongated along the earth's magnetic lines of force. Electron irregularities of scale 10 meters or smaller measured in at least one dimension transverse to the magnetic field lines, and 1,000 meters or longer measured along the magnetic field lines, are shown to exist as high as $450 \mathrm{~km}$ in the nocturnal equatorial $F$ region during equatorial spread- $F$ conditions. Equatorial spread- $F$ echoes observed at Huancayo are demonstrated to be arriving at all elevation angles in the magnetic east-west plane. The geographical extension of a given scattering sheet in the magnetic east-west direction was at times as great as $1000 \mathrm{~km}$. An observational procedure is suggested for distinguishing two fundamental varieties of spread- $F$ echoes appearing on the equatorial ionograms. A necessary condition, that the contours of mean electron density be parallel to the magnetic lines of force, is proposed as a controlling factor for the occurrence of spread $F$ in the equatorial ionosphere.

On the analysis of polarization rotation recordings of satellite radio signals, R. S. Lawrence and C. G. Little, pp. 391-399 of Some ionospheric results obtained during the International Geophysical Year; Proc. symp. organızed by the URSI/AGI committee, Brussels, 1959, edited by W.J. G. Beynon (Elsevier Publ. Co., Amsterdam, 1960).

At frequencies as low as $20 \mathrm{mc} / \mathrm{s}$ the rotation of the plane of polarization of satellite signals cannot be assumed to be proportionai to $\int \mathrm{N} B \cos \theta$ dl along the line of sight. A method of analysis is presented which eliminates this assumption and permits accurate estimates of total electron content below the satellite height to be obtained from 20 me observations. Some of the results obtained using the method to determine the sub-satellite electron content, throughout a satellite pass, are presented. These analyses permit the study of ionospheric tilts, and have revealed the presence of large-scale irregularities in the ionospheric electron content. The deviation in sub-satellite content of these irregularities is of the order
$2 \%$ of the running mean value; the lateral extent of the irregularities is of the order of a few hundred kilometers. The effects of such irregularities upon ionospheric refraction and satellite Doppler curves are briefly discussed.

Prolonged space-wave fadeouts in tropospheric propagation, A. P. Barsis and M. E. Johnson, NBS Tech. Note 88 (PB161589) (1961) \$2.00

This paper contains the results of studies performed during the last several vears on the short-term variability of tropospheric signals received over within-the-horizon paths. Signal variations of this type have been termed "prolonged spacewave fadeouts," as they are mainly characterized by reductions in signal level to many decibels below presumably constant values determined from geometrical optics methods. The data described here were obtained from measurements over propagation paths in the Pacific Coast region of Southern California, and the continental region of Eastern Colorado. Fadeouts are analyzed as a function of carrier frequency, path characteristics, and meteorological parameters. The study also includes an evaluation of fadeouts observed over a path using a mountain peak as a diffracting knife-edge like obstacle between transmitter and receiver.

The relationship of low-height ionosonde echoes to auroralzone absorption and VHF D scatter, J. K. Olesen and J. W. Wright, J. Geophys. Research 66, No. 4, 1127-1134 (A pril 1961).

Weak diffuse HF reflections at heights between 75 and 95 $\mathrm{km}$ in the auroral zone are designated $E_{s} d$. Diurnally, $E_{s} d$ occurs most frequently at noon at all seasons, and shows a pronounced minimum of occurrence around 2000 hours local time. There is little evidence for a seasonal variation from the vear's data presented here. It is suggested that $E_{s} d$ is related to the anomalies of auroral-zone absorption and that it is the layer responsible for VHF forward scatter.

The Ephi system for VLF direction finding, G. Hefley, R. F. Linfield, and T. L. Davis, J. Research NBS 65C (Eng. and Instr.), No. 1, 43-49 (Jan-Mar. 1961).

A new system of VLF direction finding has been developed and tested by the National Bureau of Standards, Boulder, Colorado. The system has been named "Ephi" (E- $\phi)$ because the bearing of the transient signal is determined from the relative phase $(\phi)$ of the vertical electrical field $(\mathrm{E})$ received at spaced antennas. The advantage of this scheme compared to conventional crossed-loop techniques is that it minimizes siting and polarization errors. A minimum of three antennas must be used to resolve directional ambiguity, and the preferred antenna location is at the vertices of an equilateral triangle with baselines equal to $1 / 3$ to $1 / 10$ wavelength (at $10 \mathrm{kc} / \mathrm{s}$ ). Appropriate phase detectors, delay lines and coincidence circuits are used to obtain a directional code in preset sectors. Within practical instrumentation limits any number of sectors of variable widths can be operated simultaneously and each can be rotated in azimuth.

Integrated starlight over the sky, F. E. Roach and L. R. Megill, Astrophysical J. 133, No. 1, 228-242 (Jan. 1961). Calculations are made of the total integrated starlight over the entire sky based on the star counts in Groningen Pub., No. 43. The results are given in both the photographic and the visual magnitude scales in tabular and graphical form.

Resonators for millimeter and submillimeter wavelengths, W. Culshaw, IRE Trans. Microwave Theory and Tech. MTT-9, No. 2, 135-144 (Mar. 1961).

Further considerations on the mm-wave Fabry-Perot interferometer are presented. Computed $Q$ values for parallel metal plate resonators indicate that at spacings around 2.5 $\mathrm{cm}$, values ranging from 60,000 at $3 \mathrm{~mm}$, to 300,000 at $0.1 \mathrm{~mm}$ wavelengths are possible. The plates must, however, be 
quite flat. These results are important for many investigations, and in particular for $\mathrm{mm}$ and sub-mm wave maser research. For the aperture per wavelength ratios possible here, diffraction effects should be small. Consideration is given to using curved reflectors or focused radiation in applications where the fields must be concentrated. For this purpose, re-entrant conical spherical resonators are treated in detail, as regards operation in the TEM mode at high orders of interference. Expressions for the $Q$ and shunt impedance are given, and high values are possible at $\mathrm{mm}$ and sub-mm wavelengths. Quasi-optical methods of coupling into and out of such a resonator are proposed, and the higher modes possible in such a resonator are considered. Results indicate that it could have application to the mm-wave generation problem, and that it represents a good resonant cavity for solid-state research at $\mathrm{mm}$ and sub-mm wavelengths, and for maser applications in particular.

The electromagnetic fields of a dipole in the presence of a thin plasma sheet, J. R. Wait, Appl. Sci. Research, Section B, 8, $397-417(1960)$.

The problem of electric and magnetic dipoles located near a thin planar slab or sheet of ionized material is considered. A constant and uniform magnetic field is impressed on the slab. Under the assumption that the thickness of the slab is very small, expressions for the resultant fields are obtained. As a result of the anisotropy of the sheet it is indicated that the fields are elliptically polarized in general. On carrying out a saddle-point evaluation of the integrals in the formal solution it is shown that the far fields may be split into "radiation" and "surface wave" components. The dependence of the radiation pattern and the surface wave characteristies on electron density, collision frequency and the impressed magnetic field is illustrated.

The Nation's electronic standards program: Where do we now stand? Harvey W. Lance, IRE Trans. Instrumentation I-9, No. 2, 94-100 (Sept. 1960).

Recently increased standards activities throughout the nation have resulted in a large increase in the calibration services requested from the National Bureau of Standards and in a number of related problems. Several of these are discussed, including desirable criteria for the staffing and instrumentation of electronic standards laboratories, the choice of interlaboratory standards to be submitted to NBS, and the use of these standards before and after calibration. An attempt is made to clarify the concept of "traceability of calibrations to NBS," and conditions under which a calibration may be called traceable are discussed. Suggestions are made regarding the use of available calibration services and the action to be taken when needed calibration services are not available. The need for an association of standards laboratories is pointed out, and many areas are noted in which such an association could make valuable contributions.

Propagation of error in a chain of standards, A. G. McNish and J. M. Cameron, IRE Trans. Instrumentation I-9, No. 2, 101-104 (Sept. 1960).

There is a widespread belief that in a chain of standards traceable back to a central laboratory, each standard must be calibrated in terms of a standard 10 times as accurate. Conversely, this implies a 10-fold degradation in accuracy in each successive calibration. If this were true, accuracy would be intolerably degraded at the working level. A more realistic view is that accuracy in a chain of standards is as good as its weakest link. This can be demonstrated by experimental data on the errors obtained in calibrations and can be explained by examining the factors which affect accuracy in calibration.

An analysis of the accumulated error in a hierarchy of calibrations, E. L. Crow, IRE Trans. Instrumentation I-9, No. Q, 105-114 (Sept. 1960).

Calibrations of many types are performed in a hierarchy of calibration laboratories fanning out from a national standard. Often the statement is made that the accuracy of each echelon of the hierarchy should be 10 times the accuracy of the immediately following echelon. The validity of such statements is examined by deriving formulas for the total error accumulated over the entire sequence when systematic and random errors may occur in each echelon, and by determining how a given total error may be achieved at minimum total cost under reasonable assumptions for the form of the cost-error functions.

Atomic beam frequency standards, R. C. Mockler, R. E. Beehler, and C. S. Snider, IRE Trans. Instrumentation I-9, No. 2, 120-132 (Sept. 1960).

A general qualitative description of atomic beam devices is given, with particular emphasis upon cesium atomic frequency standards.

The various uncertainties in frequency measurements are discussed including the effects of the uniform $C$ field, the effect of a phase difference between the two oscillating fields that excite the atomic transition, and the effect of exciting an atomic transition with signals that are not monochromatic. The two cesium beam devices constructed at the National Bureau of Standards are described in some detail. The various tests are described for determining the uncertainties in the frequency measurements. The results of these tests are given.

The accuracy of these rather dissimilar machines is considered to be $\pm 1.5 \times 10^{-11}$, and the precision of measurement is $2 \times 10^{-12}$. The latter figure represents the standard deviation of the mean for measurement times of a few hours, or, about 100 separate measurements.

The power spectrum and its importance in precise frequency measurements, J. A. Barnes and R. C. Mockler, IRE Trans. Instrumentation I-9, No. 2, 149-155 (Sept. 1960).

The power spectral density functions of a frequency multiplier chain, driven by several different crystal oscillators, were obtained by comparing the output with a second chain which was stabilized with an ammonia maser. The frequency of the maser stabilized chain was demonstrated to be relatively fixed; the power spectrum of the other chain was determined by two different methods. The results are compared. Possible errors and uncertainties introduced by the methods are discussed. An analysis is made that relates the instantaneous frequency fluctuations of a signal with the power spectral density function.

Analysis predicts that when frequency modulation occurs in the first stages of frequency multiplication or in the primary frequency oscillator, the output power spectrum is, in general not symmetrical. Furthermore, the sidebands are increased in intensity by the multiplication process. This is, in fact, observed to be the case. It is shown that a frequency counter will measure the frequency of the center of gravity of the power spectrum.

If signals having a complex power spectrum are used in precise frequency measurements, errors may result.

Standards and measurements of microwave surface impedance, skin depth, conductivity and $\boldsymbol{Q}, \mathrm{H}$. E. Bussey, IRE Trans. Instrumentation I-9, No. 2, 171-175 (Sept. 1960).

The metal walls of a cavity resonator become standards of skin depth when the internal $Q$ is determined, if the walls are uniform and if contact loss is eliminated as in the circular $\mathrm{TE}_{011}$ mode. An end plate standardized in this way may be replaced by another flat piece of material and its unknown skin depth easily determined. A copper cavity in use has 94 per cent of theoretical $Q$. Deoxidization of the surface raises the value to 97 per cent. Surface roughness and mode conversion may account for the remaining $Q$ departure. Accuracy of $Q$ measurement ( \pm 3 per cent) will be discussed and preliminary results on several metals will be given.

A radio-frequency permittimeter, R. C. Powell and A. L. Rasmussen, IRE Trans. Instrumentation I-9, No. 2, 179-184 (Sept. 1960).

A coaxial RF impedance transformer in which the secondary is a single turn of the material to be measured is used with twoterminal impedance bridges to determine the complex permittivity or complex conductivity of low-impedance materials. No electrodes are needed, and many conductors, semiconductors, electrolytes and high-permittivity materials can be evaluated to about 1 per cent, since errors due to electrode impedance and interaction as well as first-order series induct- 
ance are eliminated. The design, calibration, range, and accuracy are given along with measured values of such materials as ferrites and strong electrolytic solutions, showing complex conductivities differing considerably from those previously observed by other methods.

A transfer instrument for the intercomparison of microwave power meters, G. F. Engen, IRE Trans. Instrumentation I-9, 202-208 (Sept. 1960).

In the intercomparison of two microwave power standards, or in the calibration of a microwave power meter by means of a second or "standard" power meter, the measurement of microwave impedance has played a major role.

Through an extension of the reflectometer concept, it is now possible to devise a four-arm junction which, when properly adjusted, makes possible the intercomparison or calibration of such power meters with little or no regard for their impedance characteristics. In addition, the method is substantially independent of the impedance discontinuity which may be present at the input flange or connector. This latter result is of particular value in coaxial systems.

Absolute measurement of temperatures of microwave noise sources, A. J. Estin, C. L. Trembath, J. S. Wells, and W. C. Daywitt, IRE Trans. Instrumentation I-9, 209-213 (Sept. 1960).

In recent years, the requirement for noise-figure measurements of low-noise devices has led to a need for more precise knowledge of temperatures of noise sources. A system has been developed which is capable of measuring the absolute noise temperature of a gas discharge tube in WR-90 waveguide to within $0.01 \mathrm{db}$. The comparison circuit is a modified Dicke radiometer. The standard noise source is a black body radiator at approximately $1000^{\circ} \mathrm{C}$. Preliminary measurements of noise temperatures of a set of nine laboratory equivalents of a commonly used argon discharge tube indicate an excess noise temperature of $15.90 \mathrm{db}$ at $200 \mathrm{ma}$ discharge current with a variation between tubes of $0.03 \mathrm{db}$.

A modulated subcarrier technique of measuring microwave phase shifts, G. E. Schafer, IRE Trans. Instrumentation I-9, 217-219 (Sept. 1960).

This paper describes a technique for comparing phases of two microwave signals which employs amplitude modulation in one channel of a two-channel system. This modulated subcarrier technique produces a null response in a two-channel system for all ratios of the amplitudes of the waves traversing the separate channels. Therefore, high precision is maintained for all ratios of amplitudes. A practical application of this technique using readily available components achieved a precision of phase measurements of a tenth of a degree for a change of attenuation of $50 \mathrm{db}$ of component under test.

Measurement of reflections and losses of waveguide joints and connectors using microwave reflectometer techniques. R. W. Beatty, G. F. Engen, and W. J. Anson, IRE Trans Instrumentation I-9, 219-226 (Sept. 1960).

The reflection and loss of a waveguide joint are quantified by its VSWR and efficiency, respectively. These are conveniently and accurately determined by techniques which employ a reflectometer with auxiliary tuners and an adjustable sliding termination. Depending upon the stability and gain of the associated apparatus, measurements of VSWR's of 1.001 and lower, and of efficiencies of 99.99 per cent and higher may be obtained. The attenuations of short lengths of waveguide may be determined at the same time that the efficiency measurement is made.

A precision $\mathrm{RF}$ attenuation calibration system, C. M. Allred and C. C. Cook, IRE Trans. Instrumentation I-9, 268-274 (Sept. 1960).

A new precision attenuation calibrating system with greatly increased sensitivity, stability, and measurement range has been completed at the National Bureau of Standards, Boulder Laboratories. The increased stability and sensitivity are achieved by the use of a highly accurate piston attenuator and precision phase shifter combined into a null system. The extended attenuation measurement range has been ob- tained by using a new mode launching system which is excited by essentially a constant current source of very high magnitude. The padding necessary for correct impedance matching is kept at a minimum by use of a special noninteractive combining network.

A precision RF power transfer standard, P. A. Hudson, IRE Trans. Instrumentation I-9, 280-283 (Sept. 1960). A fast-reading, precision RF power transfer standard is described which is usable at fixed frequencies in the range $10 \mathrm{Mc}$ to $1000 \mathrm{Mc}$. The dynamic range is 1 watt to 1000 watts with a resolution of 0.1 per cent to 0.01 per cent. Stability is 0.1 per cent per year. The standard consists of three directional couplers to cover the frequency range and a series of vacuum thermoelement detectors matched to 50 ohms at each frequency interest. The thermoelements are connected to the secondary line of the appropriate coupler and provide a de output voltage which is calibrated in terms of $\mathrm{RF}$ power in the coupler main line.

A series of small, portable wattmeters employing vacuum thermoelements are also described.

\section{Other NBS Publications}

Journal of Research, Vol. 65A, No. 4, July-August 1961. 70 cents.

Electrical properties and kinetics of electrode reactions. R. J. Brodd.

Effect of hydrostatic pressure upon the relaxation of birefrigence in amorphous solids. R. M. Waxler and L. H. Adams.

Vapor pressures of platinum, iridium, and rhodium. R. F. Hampson, Jr., and R. F. Walker.

Crystallization of bulk polymers with chain folding: theory of growth of lamellar spherulites. J. D. Hoffman and J. I. Lauitzen, Jr.

Phase equilibrium relations in the binary system barium oxide-niobium pentoxide. R. S. Roth and J. L. Waring. Solid state reactions involving oxides of trivalent cations. S. J. Schneider, R. S. Roth, and J. L. Waring.

Gamma irradiation of fluorocarbon polymers. R. E. Florin and L. A. Wall.

Inhibition of diffusion flames of methyl bromide and trifluoromethyl bromide applied to the fuel and oxygen sides of the reaction zone. E. C. Creitz.

Atomic energy levels in crystals, J. L. Prather, NBS Mono. 19 (1961) 60 cents.

A spectrophotometric atlas of the spectrum of $\mathrm{CH}$ from $3000 \mathrm{~A}$ to $5000 \mathrm{~A}, \mathrm{~A}$. M. Bass and H. P. Broida, NBS Mono. 24 (1961) 20 cents.

Development of high-termperature strain gages, J. W. Pitts and D. G. Moore, NBS Mono. 26 (1961) 20 cents.

Bibliography of temperature measurement-January 1953 to June 1960, C. Halpern and R. J. Moffat, NBS Mono. 27 (1961) 15 cents.

Corrected optical pyrometer readings, D. E. Poland, J. W. Green, and J. L. Margrave, NBS Mono. 30 (1961) 55 cents.

Units of weight and measure (United States customary and metric) definitions and tables of equivalents, L. V. Judson, NBS Misc. 233 (1960) 40 cents.

Quarterly radio noise data, September, October, November 1960, W. Q. Crichlow, R. T. Disney, and M. A. Jenkins, NBS TN18-2 (PB151377-8) (1961) \$1.75.

A survey of computer programs for chemical information searching, E. C. Marden and H. R. Koller, NBS TN85 (PB161586) (1961) \$2.25.

Standards and testing, the key to quality, B. E. Foster, Eng. Bull., Purdue Univ. XLIV, No. 6, 54-62 (Nov. 1960). Subgroups of the modular group and sums of squares, M. Newman, Am. J. Math. 82, No. 4, 761-778 (Oct. 1960).

Phase equilibria in the system cadmium oxide-niobium oxide, R. S. Roth, J. Am. Ceram. Soc. 44, No. 1, 49-50 (Jan. 1961).

Redetermination of the chromium and nickel solvuses in the chromium-nickel system, C. J. Bechtoldt and H. C. Vacher, Trans. Metallurgical Soc., Am. Inst. Mining Engrs. 221, 14-18 (Feb. 1961). 
Hydrogen-bonding in calcium-deficient hydroxyapatites, A. S. Posner, J. M. Stutman, and E. R. Lippincott, Nature 188, No. 4749, 486-487 (Nov. 1960)

Hydrogen sulfide precipitation of the elements from $0.2-0.5$ normal hydrochloric acid, J. I. Hoffman, Chemist Analyst 50, No. 1, 30 (Mar. 1961).

Dielectric constant and dielectric loss of $\mathrm{TiO}_{2}$ (Rutile) at low frequencies, R. A. Parker and J. H. Wasilik, Phys. Rev. 120, No. 5, 1631-1637 (Dec. 1960).

Generating functions for formal power series in non-commuting variables, K. Goldberg, Proc. Am. Math. Soc. 11, No. 6, 988-991 (Dec. 1960).

Tests for regression coefficients when errors are correlated, M. M. Siddiqui, Ann. Math. Stat. 31, No. 4, 929-938 (Dec. 1960)

Application of the method of polarized orbitals to the scattering of electrons from hydrogen, A. Temkin and J. C. Lamkin, Phys. Rev. 121, No. 3, 788-794 (Feb. 1961).

A recommended standard resistor-noise test system, G. T. Conrad, Jr., N. Newman, and A. P. Stansbury, IRE Trans. Component Parts CP-7, No. 3, 71-88 (Sept. 1960).

On the absorption spectrum of $\mathrm{CF}_{2}$ and its vibrational analysis, D. E. Mann and B. A. Thrush, J. Chem. Phys. 33, No. 6, 1732-1734 (Dec. 1960).

Plating gun bores, V. A. Lamb and J. P. Young, Ordnance XLV, No. 245, 725-727 (Mar.-Apr. 1961).

Low temperature static seals using elastomers and plastics, D. H. Weitzel, R. F. Robbins, G. R. Bopp, and W. R. Bjorklund, Rev. Sci. Inst. 31, No. 12, 1350-1351 (Dec. 1960).

FM and SSB radiotelephone tests on a VHF ionospheric scatter link during multipath conditions, J. W. Koch, W B. Harding, and R. J. Jansen, IRE Trans. Commun. Systems CS-8, No. 3, 183-186 (Sept. 1960).

Electron scattering in high magnetic field, A. H. Kahn, Phys. Rev. 119, No. 4, 1189-1192 (Aug. 1960).

Microwave spectrum of cis-difluoroethylene, V. W. Laurie, J. Chem. Phys. 34, No. 1, (Jan. 1961).

Surface roughness of gold castings, J. J. Barone, R. L. Huff, and G. Dickson, Dental Progr. 1, No. 2, 78-84 (Jan. 1961).

The sensitivity of photographic film to $3-\mathrm{mev}$ neutrons and to thermal neutrons, M. Ehrlich, Health Phys. 4, 113-128 (1960)

A prototype rubidium vapor frequency standard, R. J. Carpenter, E. C. Beaty, P. L. Bender, S. Saito, and R. O Stone, IRE Trans. Instrumentation I-9, No. 2 (Sept. 1960).

Low even configurations in the first spectrum of thorium (Th i), R. E. Trees, Physica 26, 353-360 (1960).

Comparison measurements with intensity standards for high energy bremsstrahlung, J. S. Pruitt and W. Pohlit, Z. Naturforschung 15b, No. 9, 617-619 (1960).

High-dispersion spectra of Jupiter, C. C. Kiess, C. H. Corliss, and H. K. Kiess, Astrophys. J. 132, No. 1, 221-231 (July 1960).

Propagation of electromagnetic waves along a thin plasma sheet, J. R. Wait, Can. J. Phys. 38, 1586-1594 (1960).

Preparation and properties of aromatic fluorocarbons, W. J. Pummer and L. A. Wall, J. Chem. Engrs. Data 6, No. 1, 76-78 (Jan. 1961).

Stability of thermoset plastics at high temperatures, S. L. Madorsky and S. Straus, Modern Plasties 38, 134-140 (Feb. 1961).

Immiscibility and the system lanthanum oxide boric-oxide, E. M. Levin, C. R. Robbins, and J. L. Waring, J. Am. Ceram. Soc. 44, No. 2, 87-91 (Feb. 1961).

On the properties of the vapor pressure curve, E. H. Brown, Cryogenics 1, No. 1, 37-40 (Sept. 1960).

Absorption and scattering of photons by holmiun and erbium, E. G. Fuller and E. Hayward, Proc. Intern. Conf. Nuclear Structure, 761-766 (Kingston, Canada, 1960).

Spectroscopy of fluorine flames. I. Hydrogen-fluorine flame and the vibration-rotation emission spectrum of $\mathrm{HF}, \mathrm{D} . \mathrm{E}$. Mann, B. A. Thrush, D. R. Lide, J. J. Ball, and N. Acquista, J. Chem. Phys. 34, No. 2, 420-431 (Feb. 1961).

The absorption spectra of magnesium and manganese atoms in solid rare gas matrices, O. Schnapp, J. Phys. Chem. Solids 17, Nos. 3/4, 188-195 (1961).
The Franck-Condon factor $\left(\mathrm{q}_{\mathrm{v}}{ }^{\prime}{ }_{\mathrm{v}}{ }^{\prime \prime}\right)$ array to high vibrational quantum numbers for the $\mathrm{O}_{2}\left(\mathrm{~B}^{3} \Sigma_{\mathrm{u}}-\mathrm{X}^{3} \Sigma_{\mathrm{g}}^{+}\right)$Schumann-Runge band system, R. W. Nicholls, Can. J. Phys. 38, 1705-1711 (1960).

NBS source of American Standards, W. A. Wildhack, ISA J. 8, No. 2, 45-50 (Feb. 1961).

Ionospheric mapping by numerical methods, W. B. Jones and R. M. Gallet, Telecommun. J. 12, 260-264 (Dec. 1960).

The activation energy for hydrogen atom addition to propylene, M. D. Scheer and R. Klein, J. Phys. Chem. 65, $375-377$ (1961).

Intramolecular rearrangements. I. sec-butvl acetate and sec-butvl formate, R. Borkowski and P. Ausloos, J. Am. Chem. Soc. 83, No. 5, 1053-1056 (Mar. 1961).

Titanium (III) chloride and titanium (III) bromide (titanium trichloride and titanium tribromide), J. M. Sherfey, Chapter IVB, Sec. 17, p. 57-61, Book, Inorganic Syntheses, by E. G. Rochow (McGraw-Hill Book Co., New York, N.Y., 1960).

Science news writing, D. M. Gates and J. M. Parker, Science 133, No. 3447, 211-214 (Jan. 1961).

Elastomers for static seals at cryogenic temperatures, D. H. Weitzel, R. F. Robbins, G. R. Bopp, and W. R. Bjorklund, Rev. Sci. Insts. 31, No. 12, 1350-1351 (Dec. 1960).

New standards for the space age, A. T. McPherson, Astronautics 6, No. 1, 24-25; 50-54 (Jan. 1961).

Near infrared atmospheric transmission to solar radiation, D. M. Gates, J. Opt. Soc. Am. 50, No. 12, 1299-1304 (Dec. 1960)

Determination of crystallite size distributions from X-ray line broadening, A. Bienenstock, J. Appl. Phys. 32, No. 2, 187-189 (Feb. 1961)

Correlation of visual and subvisual auroras with changes in the outer Van Allen radiation zone, B. J. O'Brien, J. A. Van Allen, F. E. Roach, and C. W. Gartlein, IGY Bull., No. 45, 1-16 (Mar. 1961)

Arc source for high temperature gas studies, J. B. Shumaker, Jr., Rev. Sci. Instr. 32, No. 1, 65-67 (Jan. 1961).

The dependency of the melting temperature of bulk homopolymers on the crystallization temperature, L. Mandelkern, J. Polymer Sci. XLVII, issue 149, 494-496 (July 1960).

Spiral patterns in geophysics, V. Agy, J. Atmospheric and Terrest. Phys. 19, 136-140 (1960).

Iron $(99.9+)$, G. A. Moore and T. R. Shives, Metals Handb. 1, 1206-1212 (1961).

The interfacial properties of polyesters at glass and water surfaces, R. R. Stromberg, Soc. Plastic Engr. 15, 882-886 (Oct. 1959)

Ionospheric absorption at times of auroral and magnetic pulsations, W. H. Campbell and H. Leinback, J. Geophys. Research 66, No. 1, 25-34 (Jan. 1961).

Some properties of new or modified excitation sources, M. Margoshes, Am. Soc. Testing Materials, Spec. Tech. Publ. 259, 46-58 (1959).

Seasonal and day-to-day changes of the central position of the $S_{q}$ overhead current system, S. Matsushita, J. Geophys. Research 65, No. 11, 3835-3839 (Nov. 1960)

Hydrogen sulfide precipitation of the elements from $0.2-0.5$ normal hydrochloric acid, J. I. Hoffman, Chemist-Analyst 50, No. 1, 30 and 32 (Mar. 1961).

The mechanism of electrolytic deposition of titanium from fused salt media, W. E. Reid, J. Electrochem. Soc. 108, No. 4, 393-394 (Ápr. 1961).

Studies of elevated temperature corrosion of type 310 stainless steel by vanadium compounds, H. L. Logan, Corrosion 17, 109-111 (Apr. 1961).

Deep penetration of radiation, U. Fano and M. J. Berger, Proc. Symp. Appl. Math. XI 43-59 (1961).

Deposition of iron from salts of fluoro-acids, J. H. Connor and V. A. Lamb, Plating 48, No. 4, 388-389 (Apr. 1961). Calculation of properties of magnetic deflection systems, S. Penner, Rev. Sci. Insts. 32, No. 2, 150-160 (Feb. 1961). A simple low-temperature specimen holder for an X-ray diffractometer, D. K. Smith, Norelco Reporter VII, No. 1, 11-12 (Jan.-Feb. 1961)

Stepless variable resistor for high currents, C. R. Yoklev and J. B. Shumaker, Jr., Rev. Sei. Instr. 32, No. 1, 6-8 (Jan. 1961). 
Microbalance techniques for high temperature application, R. F. Walker, Book, Vacuum Microbalance Techniques, edited by M. J. Katz, I, 87-110 (Plenum Press Inc., New York, N.Y., 1961).

Investigation of bond in beam and pull-out specimens with high-yield-strength deformed bars, R. G. Mathey and D. Watstein, J. Am. Concrete Inst. 32, No. 9, 1071-1090 (Mar. 1961).

Vacuum ultraviolet photolysis of ethane: Molecular detachment of hydrogen, H. Okabe and J. R. MeNesby, J. Chem. Phys. 34, No. 2, 668-669 (Feb. 1961).

Shielding calculations for civil defense, C. Eisenhauer, Health Phys. 4, No. 2, 129-132 (1960).

Hydrogen atom reactions with propene at $77^{\circ} \mathrm{K}$. Disproportionation and recombination, R. Klein and M. D. Scheer, J. Phys. Chem. 65, 324-325 (1961).
The effect of solvents of the $\gamma$-ray radiolysis of methyl acetate and acetone, P. Ausloos, J. Am. Chem. Soc. 83, No. 5, 1056-1060 (Mar. 1961).

On the nature of the crvstal field approximation, C. M. Herzfeld and H. Goldberg, J. Chem. Phys. 34, No. 2, 643-651 (Feb. 1961).

A study of auroral coruscations, W. H. Campbell and M. H. Rees, J. Geophys. Research 66, No. 1, 41-55 (Jan. 1961).

* Publications for which a price is indicated (except for Technical Notes) are available nly from the Superintendent of Documents, US. Government Printing Office, Washinoton 25, D.C. (foreign postage, one-fourth additional). Technical Notes ar available only from the Office of Technical Services, U.S. Department of Commerce, Washington 25, D.C. (order by PB number). The Technical News Bulletin and Basic Radio Propagation Predictions are available on a 1-, 2-, or 3-year subscriptron basis, although no reduction in ratcs can be made. Reprints from outside journals and the NBS Journal of Research may often be obtained directly from the authors. 